\title{
Was there Abnormal Trading in the S\&P 500 Index Options Prior to the September 11 Attacks?
}

\author{
Wing-Keung Wong ${ }^{*}$ \\ Hong Kong Baptist University, Hong Kong \\ Howard E. Thompson \\ University of Wisconsin-Madison, USA \\ Kweehong Teh \\ National University of Singapore, Singapore
}

\begin{abstract}
After the September 11 attacks, several major newswires reported that there were insiders who tried to profiteer from the options market in anticipation of the event. We use the Student's t-statistics and several non-parametric statistics to test whether there was abnormal trading in S\&P 500 (SPX) index options prior to the September 11 attacks. Our findings from the out-of-the-money (OTM), at-the-money (ATM) and in-the-money (ITM) SPX index put options and ITM SPX index call options lead us to reject the null hypothesis that there was no abnormal trading in these contracts prior to the September 11 attacks. We also find evidence consistent with three bearish speculation strategies, namely the Put Purchase strategy, the Put Bear Spread strategy, and the Naked ITM Call Write strategy. In addition, we conclude that there is evidence of abnormal trading in the September 2001 OTM, ATM and ITM SPX index put options immediately after the 9-11 attacks. We also employ the CBOE VIX to confirm the conclusion drawn from the call and put options. This, in turn, is consistent with insiders anticipating the 9-11 attacks.
\end{abstract}

* Wing-Keung Wong, Department of Economics, Hong Kong Baptist University, Kowloon Tong, Hong Kong. Tel: (852)-3411-7542, Fax: (852)-3411-5580, Email: awong@hkbu.edu.hk

The authors are grateful to Professor Panayiotis Theodossiou for his substantive comments that have significantly improved this manuscript. The first author would like to thank Professors Robert B. Miller and Howard E. Thompson for their continuous guidance and encouragement. The research is partially supported by Hong Kong Baptist University, University of Wisconsin-Madison, and the National University of Singapore. The first author wishes to acknowledge the financial support of grant \#202809 from the Research Grants Council of Hong Kong.

(Multinational Finance Journal, 2011, vol. 15, no. 1/2, pp. 1-46)

(C) Multinational Finance Society, a nonprofit corporation. All rights reserved.

DOI: $10.17578 / 15-1 / 2-1$ 
Keywords: 9-11 attacks, put options, call options, SPX index, Student's t-statistics, non-parametric statistics.

\section{Introduction}

This study is motivated by several major newswire stories which reported that there were insiders who tried to profiteer from the options market in anticipation of the September 11 (9-11) attacks. ${ }^{1}$ For example, on September 19, 2001, the Washington Post reported that the Chicago Board Options Exchange (CBOE) was investigating trading before the 9-11 attacks on the United States and suggested that abnormal trading may have taken place on options on selected airlines stocks, presumably because the value of these stocks was expected to react immediately to the 9-11 attacks. Poteshman (2006) analyzed the airline data and concluded that there is evidence of unusual option market activity in the days leading up to September 11 that is consistent with investors trading on advance knowledge of the attacks. To complement of the study by Poteshman (2006), we study the options volume on the Standard \& Poor's 500 Index (SPX index options) to address the issue.

We examine the options volume on the SPX instead of analyzing the airline data due to the following reasons: Firstly, the airline data have been well studied by Poteshman (2006). Secondly, any 9-11 insider would not trade directly the airline options in large volume to avoid drawing attention after the 9-11 attacks. The CBOE has records of who trades in option contracts thus creating an expectation of sure detection. Thirdly, with the benefit of hindsight, the aftermath of the 9-11 attacks was not confined to the airlines directly involved in the attacks. We note that other industries that were hardest hit by the 9-11 attack were insurance, particularly the reinsurance, hotels and some other related industries that in turn influenced the performance of the whole stock market (Virgo, 2001). Arvedlund (2001) supported this viewpoint and suggested that terrorist conspirators could have profited more from the fall of entire market than single stocks. Hence, we consider it to be more

1. For example, see Simon Clow, "French Market Regulators Raise Vigilance after US Attacks," Dow Jones International News, September 17, 2001; Jana Sanchez, "Dutch traders Report Unusual Trade in KLM Options," Reuters News, September 17, 2001; Balz Bruppacher, "Swiss Banking Commission Investigates Insider Dealing before US Terror Attacks," September 19, 2001; Marcy Gordon, "SEC Investigates Possible Market Manipulation by Terrorists; No Conclusions Yet," AP Newswires, September 19, 2001. 
appropriate to address the issue in relation to the stock market as a whole instead of focusing on a few companies or confining our analysis only to the airline sector. In addition, we believe that 9-11 will affect the blue chips more than the small stocks and thus we study the options volume on the Standard \& Poor's 500 Index to address the issue.

The objective of this study is to test the hypothesis of abnormal trading in the options markets prior to the 9-11 attacks on the United States. Investors have used SPX index options for close to two decades to manage their risk exposure to the equity market or to speculate in movements in the equity market. SPX index options, which are traded on CBOE, offer readily available and flexible tools to reap speculative gains in the aftermath of the attacks for investors who have prior knowledge about the 9-11 attacks. If there were insiders who tried to profit from the options market in anticipation of the 9-11 attacks, they might buy put options or sell call options of the September 2001 SPX, which would result in an increase in the corresponding trading volume. In this regard, as we are unable to test directly whether there were indeed insiders anticipating the 9-11 attacks, we will test whether there was any abnormal trading volume in September 2001 SPX index put options and call options prior to the 9-11 attacks. The results lead us to reject the hypothesis that there was no abnormal volume. This, in turn, is consistent with insiders anticipating the 9-11 attacks.

Our findings from the out-of-the-money (OTM), at-the-money (ATM) and in-the-money (ITM) SPX index put options and ITM SPX index call options suggest that there was no evidence of abnormal trading in September 2001 OTM SPX index put options during the window extending from first day of trading up to 3 calendar months prior to the 9-11 attacks. However, there was abnormal trading in these contracts within 3 calendar months prior to the September 11 attacks, and it was likely the insiders adopted three bearish speculation strategies, namely the Put Purchase strategy, the Put Bear Spread strategy, and the Naked ITM Call Write strategy. In addition, we find that there was evidence of abnormal trading in the September 2001 OTM, ATM and ITM SPX index put options immediately after the 9-11 attacks and before the expiration date. This suggests that owning a put was a valuable investment and those who owned them could sell them for considerable profit before the expiration date. This would spur trading by those who were eager to garner the profit and exit the market and is consistent with the hypothesis that there were investors who tried to profit from economy-wide impacts following the 9-11 attacks. We 
also employ the CBOE VIX to confirm the conclusion drawn from the call and put options.

In a nutshell, our findings reject the null hypothesis about the absence of abnormal trading volume, which might suggest the work of insiders. We note that our findings do not prove definitively that there were insiders who tried to profit from the options market in anticipation of the 9-11 attacks; instead, our findings only provide evidence that supports the possibility of insiders attempting to profiteer from the options market in anticipation of the 9-11 attacks. We do not deny the possibility of an alternative explanation about the abnormal trading volume, that is that the abnormal trading volume might be due to a falling market and other factors that contribute to a negative market outlook. We shall address this issue in the conclusions section to underscore our argument about the possibility of insiders at works in anticipation of the 9-11 attacks.

The rest of the paper is organized as follows: Section II reviews the relevant literature and section III describes options trading strategies which form the basis for postulating hypotheses for testing in this study. Section IV elaborates on the methodology of study and hypotheses postulated. Section V describes the data used in this study and explains the findings, and section VI concludes.

\section{Literature Review}

\section{A. Event Study}

An important characteristic of a successful event study is the ability to identify precisely the date of the event as indicated in MacKinlay (1997) since in cases where the event date is difficult to identify or the event date is partially anticipated, studies have been less successful. In our case, the focal date of the event is clearly determined as September 11, 2001, the day where the attacks occurred in the United States. Event studies in which there is a single calendar date as opposed to a relative date for each data point present the problem of identifying the cause of market movements from many possible drivers.

In our case we must carefully examine the other potential causes of increased volume in the period prior to the 9-11 attack. While the stock market was falling as it had in 2000, there were differences in other economic variables between the two years. Interest rates had fallen, 
particularly at the low end and middle of the term structure. The GDP was continuing to decline and unemployment had risen over the year 2001 in contrast to 2000.

\section{B. Characteristic of Options Trading}

Trading of options contracts typically intensifies as the contracts near expiration due to traders closing out their positions or rolling them out one month to the next contract. Trading activities in September 2001 SPX index options examined in this study contain two potentially confounding factors: firstly, increases and shifts in trading activities driven by the dynamics of hedging and speculation programs as the contracts approach the expiration date; and secondly, increases in trading activities by virtue of the increased volatility associated with the "triple witching day" effect. Each of these factors is affected by the degree of moneyness of the option. Hence, we move on to review the literature relating whether an option is in-, at-, or out-of the money, and trading volume and volatility. We also look at trading strategies designed to deal with these aspects of "moneyness."

The literature documents decreased volume for both OTM and ITM options, increased volatility around expiration dates, and a variety of strategies designed to deal with volume and volatility. The relationship between moneyness and volume is not symmetrical as ATM options move into the money or out of the money (Etling and Miller 2000). Based on a sample of options on the S\&P 100 Index (OEX) and the SPX, and three liquidity proxies (volume, time between trade, and dollar bid-ask spreads), Etling and Miller found that the liquidity generally decreased as option strike prices moved either deeper in-the-money or deeper out-of-the-money. In addition, they found that in the sample of OEX and SPX calls, the OTM options had higher relative volumes than the ITM options. Stock market crises may also induce high trading volume in OTM puts; e.g. after the 1987 stock market crash, US fund managers bought more OTM puts to insure against their exposure due to the failure of futures-based portfolio insurance strategies (Gemmill 1996). Liquidity then seems to be positively related to the option (put or call) being out of the money.

Since all positions have to be sold and re-established on a "triple witching day," the markets are usually volatile, which in turn increases the uncertainty about prices of the underlying assets. Large additional volume also results from stock options being exercised. There is an 
increase in simultaneous purchase of index futures and sale of a basket of stocks, or vice versa, index arbitrage, with the unwinding of large volumes of stocks. During this process some investors would be trying to unscramble whether to roll over their existing positions in options or futures contracts, or to get into different positions. Volume and volatility are increased during these times.

There is also a volatility effect around expiration dates. Day and Lewis (1988) calculated implied volatility from index option prices around index options and futures expirations in the period March 1983 to December 1986. They found a noticeable increase in implied volatility around both quarterly and monthly (non-quarterly) expirations, probably due to covering of arbitrage positions in either index options or individual options and the underlying stocks. The higher anticipated volatility before quarterly expirations compared to non-quarterly expirations was most likely due to the unwinding of futures-related arbitrage positions.

To study the evidence for insider trading around 9-11, we concentrate on strategies that use ITM, OTM and ATM options as a decision variable. ${ }^{2}$ Trading strategies using ITM, OTM and ATM options yield different return and risk profiles. For example, Trennepohl and Dukes (1981) showed that writing calls or buying puts yields reduction of risk and return compared with the unprotected stock positions, this is as expected. Their analysis of the relative return and risk of options strategies found that buying OTM options is highly risky and unprofitable, though buying longer-term ITM options provides the largest mean returns of all strategies while being subjected to the highest risk. Fernandes and Machado-Santos (2002) found that the OTM covered call option stands out as having the most positive performance measure; the ATM put option provides the best return-risk combination, while the ITM protective put strategy seems to be more expensive.

In view of the bearish market around 9-11, we focus on the use of OTM and ITM options for speculative gains, although we note that ITM options (as well as ATM options) are largely impractical or inferior tools to speculate in a bearish market. The poor profitability of OTM options as shown by Trennepohl and Dukes suggests that increasing

2. Many studies have worked on the merits of combining options with stock portfolios, see for example, Merton et al. (1978, 1982), Yates and Kopprasch (1980), Morard and Naciri (1990) and Isakov and Morard (2001). 
volume in OTM options would be irrational in the normal course of events. Thus the presence of elevated volume would suggest something other than the normal course of events. We use this idea in our tests.

\section{Options Trading Strategies}

In this section, we describe some trading strategies and institutional characteristics of trading SPX index options. ${ }^{3}$ Broadly, options trading strategies may be categorized into bullish strategies, bearish strategies and neutral strategies. We only outline bearish strategies below as the focus of this study is bearish strategies consistent with the fact that one would be bearish about the market if one tried to profit in anticipation of the 9-11 event. ${ }^{4}$

There are several trading strategies that are relevant. Providing leverage in the case of a downward move by the underlying asset, the purchase of a put option (Put Purchase strategy) is a cheaper alternative to short-selling the underlying asset and it is the simplest way to profit when the price of the underlying asset is expected to decline. The OTM put offers both higher reward and higher risk potentials than the ITM put if the underlying asset drops substantially in price. However, should the underlying asset decline only moderately in price, the ITM put often proves to be the better choice than the OTM put because of the relative price differential. Therefore, unless speculators anticipate a very substantial decline in the price of the underlying asset, they would do best to purchase ITM puts. Also, when the speculators are purchasing ITM puts, they may often consider buying the longest-term put since the time value premium is small when compared to the time premium in the nearer-term puts. Thus an increase in the volume of put purchases for the short term suggests unusual circumstances.

The Naked (or Uncovered) Call Write strategy involves selling a call option without owning the underlying assets. But an aggressively bearish investor may buy an OTM put on one hand and "finance" the purchase of the put through the premium obtained by shorting an OTM call naked (Synthetic Short Sale strategy). The OTM put gives the investor the opportunity for substantial profits in a price decline of the

3. "Product Specifications: SPX S\&P 500 Index Options." Chicago Board of Options Exchange, (CBOE), www.cboe.com

4. One may refer to Hull (1998) for more detailed discussion of other strategies. 
underlying assets, while the sale of the OTM call would provide profits if the underlying assets stay below the strike price of the call.

A Call Bear Spread strategy involves simultaneously selling a call with a lower strike price and buying a call at a higher strike price while a Put Bear Spread strategy involves selling a put at a lower strike price while buying a put at a higher strike price. Put bear spreads are superior to call bear spreads because with the put spread, the investor is selling an OTM option and therefore does not risk early exercise of the written option before the spread becomes profitable (that is the underlying assets drop below the lower strike price). On the other hand, in the call spread, the investor sells an ITM call and thus could be at risk of early exercise before the spread has a chance to become profitable. In addition, if the price of underlying asset drops rapidly, thus rendering both legs of the put spread ITM, the put spread would normally widen quickly as well because put options tend to lose time value premium rather quickly when they go into-the-money. In contrast, the short call in a call spread may actually pick up time value premium as the underlying assets fall close to the lower strike price, thus diminishing the performance of the call spread on a quick downward movement.

The institutional characteristics revolve around the rules of the CBOE. CBOE requires each member (other than a market-maker) or member organization that maintains an end of day position in excess of 100,000 contracts in SPX index options (either for its proprietary account or for the account of a customer) to report certain information to the Department of Market Regulation. The member must report information as to whether such position is hedged and, if so, a description of the hedge employed. A report must be filed when an account initially meets the threshold of 100,000 contracts; thereafter, a report must be filed for each incremental increase of 25,000 contracts. Any significant change to the hedge must also be reported. Any speculation using the SPX index options is therefore likely to be conducted within the "constraints" of this regulatory oversight framework. One may wonder why 9-11 insiders have not been found by now since it would be easy to identify large accounts which must be reported to the CBOE Department of Regulation. We believe there are many ways to escape identification. For example, the insiders could trade small numbers of contracts. These could be traded under multiple accounts to avoid drawing attention to large trading volume under a single large account. They could also trade small volume in each contract but trade more contracts to avoid drawing attention. As open 
interest increases, non-insiders may detect a perceived signal and increase their trading activity. Insiders can then come back to enter into more transactions based on a seemingly significant trading signal from the market. In this regard, it would be difficult for CBOE to ferret out the insiders from the non-insiders as both are trading heavily.

McMillan (1996) emphasized the need to screen out increases in trading volume of a stock's options attributable to irrelevant factors (e.g. arbitrage or spread trading) in order to zero in on speculative trading. Drawing from actual trading experience, he advanced a number of rule-of-thumb methods to screen out irrelevant data vis-à-vis options on stocks. For example, one rule-of-thumb prescribes that "high-volume" situations should be defined as situations in which the daily total option volume is greater than double the average (say, 20-day moving average) option volume; and where the options are normally very active, an even greater ratio may be applicable. Another rule-of-thumb says that a situation whereby a large amount of the daily volume is being contributed by deep ITM options is unlikely to involve speculation because insiders will normally attempt to buy the cheapest options possible (that is ATM or OTM options) in order to maximize the leverage. A third rule-of-thumb revolves around the fact that speculators with insider information will buy the near-term options as they are cheaper in price and are generally the most liquid contracts, hence maximizing the leverage. In contrast, institutions often prefer far-term options, writing call options with several months of life remaining or buying mid-term puts as protection. There is a proviso in that unless the volume is at least three or four times the average volume, one should discount near-term options which are going to expire in a matter of days as the majority of volume are simply due to rolling down of contracts one month to the next contract.

Given the framework we have spelled out to this point we move on to describe our methodology.

\section{Methodology}

We postulate several hypotheses on the basis of the institutional characteristics and bearish trading strategies outlined in section III. In postulating these hypotheses, we need to define an appropriate benchmark of "normal" trading volume, as well as to distinguish abnormal trading volume attributable to a market which is in overall 
decline from insiders trading on anticipated market fallout due to the impending 9-11 attacks. These issues are inter-related and we deal with them in two ways: Firstly, we test the volumes based on the comparison of the periods prior to 9-11 attacks in 2001 with the corresponding periods in 2000. Our rationale for defining the trading volume in the corresponding periods in 2000 as the benchmark is that the equity market declined starting from the first quarter of 2000 and continued well into 2001, therefore the post-Q1 2000 market trend exhibited a pattern similar to that in 2001. Secondly, we compare the volume of the options in the post-9-11 period in 2001 with the corresponding period in 2000. If the volume prior to 9-11 attacks in 2001 is significantly greater than that of the period in 2000, we would have evidence that is consistent with a cause other than a falling equity market. Note that we only use the period in 2000 for the comparison since in years immediately before 2000, the equity market was on the rise on the whole and thus exhibited substantially different patterns.

If there were insiders who tried to profit from the options market in anticipation of the 9-11 attacks, their action would lead to a substantial decline in the equity market as a whole. The literature suggests that they might buy OTM puts under the Put Purchase strategy and/or the Synthetic Short Sale strategy, and/or sell OTM puts to set up a Put Bear Spread. The literature also suggests that there might be other insiders who, for one reason or another, anticipate a moderate decline in the equity market post-9-11 attacks, and therefore bought ITM or ATM puts instead. Hence, we postulate Hypothesis P1 as follows:

Hypothesis P1: Mean trading volume in September 2001 (short term) OTM, ATM and ITM SPX index put options prior to the 9-11 attacks does not differ from normal mean trading volume of OTM SPX index put options.

If the insiders adopted the Synthetic Short Sale strategy, the literature suggests that they would have written OTM calls in order to finance the purchase of OTM put. There is also a possibility that some well-endowed insiders might write deep OTM call in order to cream off the premium (Naked Call Write strategy). It is also possible for well-endowed insiders to adopt the Naked Call Write strategy by writing ITM or ATM calls. We therefore postulate Hypothesis C1 as follows:

Hypothesis C1: Mean trading volume of September 2001 OTM, 
ATM and ITM SPX index call options prior to the 9-11 attacks does not differ from normal mean trading volume of OTM SPX index call options.

In regard to the period following 9-11 but preceding the expiration date, we need a slightly different point of view. Formerly OTM put options that are now in the money should have increased in value. Since all investors knew of the 9-11 events in the post-9-11 period, an increase in the abnormal trading volume in the period against the corresponding period in 2000 should occur as those holding the former OTM puts which are now in-the-money would want to sell and reap the profits. The significant decline in the SPX Index post-9-11 attacks offered investors opportunity to profit from the options markets. Hence, we also test whether investors traded heavily in the options markets post-9-11 attacks and therefore postulate Hypotheses P2 and C2 as follows:

Hypothesis P2: Mean trading volume of September 2001 OTM, ATM and ITM SPX index put options post-9-11 attacks does not differ from normal mean trading volume of corresponding OTM, ATM and ITM SPX index put options.

Hypothesis C2: Mean trading volume of September 2001 OTM, ATM and ITM SPX index call options post-9-11 attacks does not differ from normal mean trading volume of corresponding OTM, ATM and ITM SPX index call options.

We also include the following two hypotheses as a control study:

Hypothesis P0: Mean trading volume of September 2001 OTM, ATM and ITM SPX index put options far before the 9-11 attacks does not differ from normal mean trading volume of corresponding OTM, ATM and ITM SPX index put options.

Hypothesis C0: Mean trading volume of September 2001 OTM, ATM and ITM SPX index call options far before the 9-11 attacks does not differ from normal mean trading volume of corresponding OTM, ATM and ITM SPX index call options.

Besides using the test on trading volume of options, we also analyze the CBOE VIX which can be seen as the implied volatility, or volatility 
forecast, for the stock market. The CBOE VIX is a measure of implied or expected future volatility, and is used as the market consensus forecast of stock market volatility for the next 30 days. The VIX is calculated by taking a weighted average of implied volatilities of 4 at-the-money puts and 4 at-the-money calls with an average time to maturity of 30 days. All 8 options are listed on the CBOE's OEX (The OEX is an index of 100 of the largest capitalized stocks whose options are traded on the $\mathrm{CBOE}$ ). An increased volatility measure should produce increased option trading volume. This leads to the following hypotheses:

Hypothesis V1: Mean VIX prior to the 9-11 attacks does not differ from normal mean VIX;

Hypothesis V2: Mean VIX post 9-11 attacks does not differ from normal mean VIX;

Hypothesis V0: Mean VIX far before the 9-11 attacks does not differ from normal mean VIX.

where $\mathrm{V} 0$ is the control hypothesis.

The event date has been exogenously determined for us, that is on September 11, 2001, the day when the 9-11 attacks took place. We define the event window to encompass all active trading days in the relevant September 2001 SPX index options contracts. The variable of interest which we examine is the trading volume in each relevant September 2001 SPX index options contract; any extraordinarily heavy volume would not be consistent with the hypothesis that insiders were absent from the market in anticipation of the event.

We define the range of daily SPX index closing price $\pm 1 \%$ as ATM. For put options, the range in which the strike prices are south (north) of the daily SPX index closing price minus (plus) $1 \%$ defines OTM (ITM) put options. Conversely, for call options, the range in which the strike prices are north (south) of the daily SPX index closing price plus (minus) $1 \%$ defines OTM (ITM) call options. Our defined range falls within the range enveloped by single-point ATM estimates implied by Harvey and Whaley (1991) at the floor, and the more generous $\pm 10 \%$ range implied by Fernandes and Machato-Santos (2002) at the ceiling.

We adopt two measures to mitigate the effects of the two potentially 


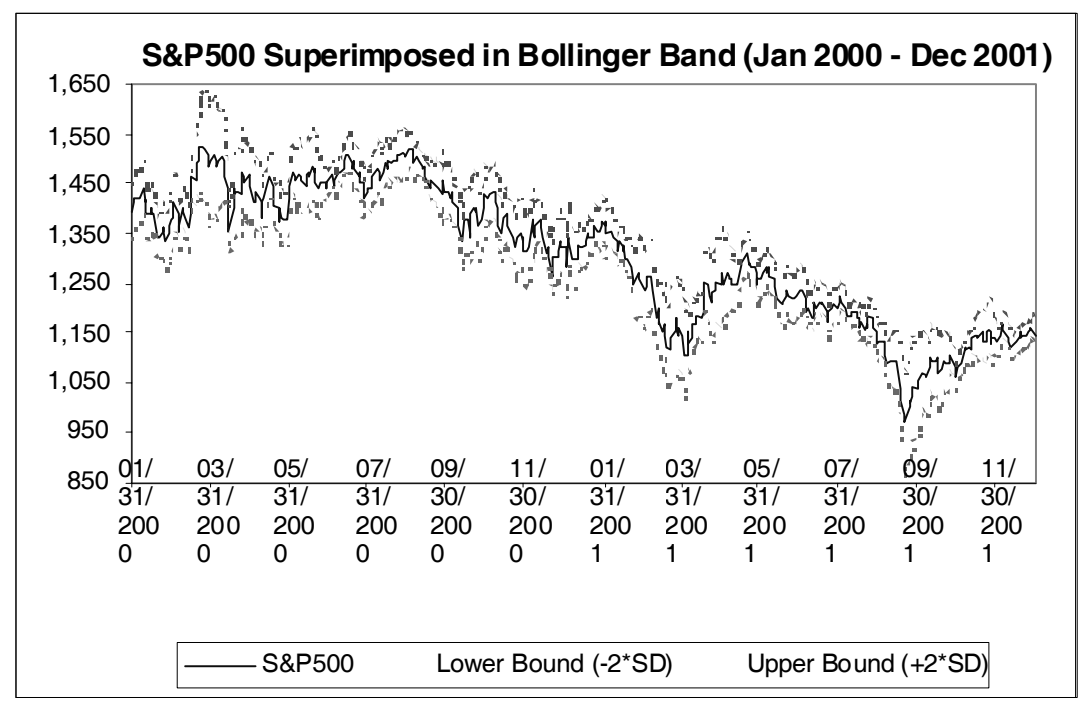

FIGURE 1.- S\&P 500 Index Superimposed in Bollinger Band (January 2000 to December 2001)

confounding factors described in section III. Firstly, we use the Bollinger Bands method to ascertain the range of strike prices to be included under this study. The (20-day) moving average price accounts for the trend in price movement. As the upper and lower envelopes fluctuate in tandem with two standard deviation $( \pm 2 \sigma)$ of the moving average price - widening in volatile markets and narrowing in quiet markets - the Bollinger Bands method automatically corrects for relative volatility of market activities at different points in time. The two-standard-deviation Bollinger Bands envelopes a range of strike prices exceeding $\pm 15 \%$ of daily prices, thus the range is sufficiently wide to cover deep ITM and deep OTM contracts which are of interest in this study (Sheikh 1989).

Figure 1 depicts the Bollinger Band constructed around the S\&P 500 closing price for the period of January 2000 to December 2001. During the 2-year period starting Jan 3, 2000, the SPX peaked at 1,527.46 on Mar 24, 2000, and went on a downward trend all the way up to and ending Dec 31, 2001. Based on the Bollinger Band, we include a total of 52 September 2001 contracts in this study (That is the strike prices ranging from 860 to 1370).

Secondly, we choose the September 2000 expiration month as the 
estimation window in order to mitigate the potentially confounding effect of "triple witching day" in September 2001 expiration month. Using the Bollinger Band method, we include the range of strike prices from 1300 to 1640 (a total of 35 contracts). The excess of 17 contracts in the September 2001 range over that of September 2000 clearly indicates that the S\&P 500 closing prices were much more volatile in the lead-up to September 2001 compared to the corresponding period in 2000 .

Many parametric tests (for example, Student's t-tests, bootstrapped Johnson's skewness-adjusted t-statistics, simulated empirical p-values) and non-parametric tests could be used for the study in this paper. We choose to use the simple tests - the Student's t-tests with and without the assumption of equality of variances - as our dataset is reasonably large and the inference is valid by virtue of the central limit theorem. In order to verify the results of the Student's t-tests, we also relax the assumption that the volume of trading in option contracts is independent and identically distributed (i.i.d.) as a normal distribution, and carry out several non-parametric tests. ${ }^{5}$ As the power of non-parametric tests is usually lower than the power of the parametric tests, we only report the results of Wilcoxon Two-Sample Test in this paper as a reference to verify the results from the Student's t-test. ${ }^{6}$

Let $X_{1}, X_{2}, \ldots, X_{n_{x}}$ be the sample volumes with mean $\mu_{x}$, variance $\sigma_{x}^{2}$ and sample size $n_{x}$ for the period under study in 2001 and let $Y_{1}, Y_{2}, \ldots, Y_{n_{y}}$ be the sample volumes with mean $\mu_{y}$, variance $\sigma_{y}^{2}$ and sample size $n_{y}$ for the period under study in 2000 . We first use the $F\left(=S_{x}^{2} / S_{y}^{2}\right)$ statistic to test whether $\sigma_{x}^{2}=\sigma_{y}^{2}$. If the hypothesis of equal variance is not rejected, we will apply the t-statistic with the assumption of equal variances such that:

$$
T=\frac{\bar{X}-\bar{Y}}{s_{p} \sqrt{\frac{1}{n_{x}}+\frac{1}{n_{y}}}}
$$

5. The non-parametric tests include Wilcoxon Two-Sample Test, Kruskal-Wallis Test, Median Two-Sample Test, Van der Waerden Two-Sample Test, Savage Two-Sample Test, Kolmogorov-Smirnov Two-Sample Test, Cramer-von Mises Test and the Kuiper Two-Sample Test. One may refer to Hollander and Wolfe (1973) for the definitions of these non-parametric statistics.

6. We skip reporting the results of all other non-parametric tests as these results draw qualitative same conclusion. The results are available on request. 
where $s_{p}^{2}$ is the pooled estimate of $\sigma^{2}$, the variance of the volume. If the null hypothesis is true, the t-statistic will follow a t-distribution with $\left(n_{x}+n_{y}-2\right)$ degrees of freedom.

However, if the hypothesis of equal variances is rejected, we will then apply the t-statistic without the assumption of equal variances such that

$$
T=\frac{\bar{X}-\bar{Y}}{\sqrt{\frac{s_{x}^{2}}{n_{x}}+\frac{s_{y}^{2}}{n_{y}}}}
$$

where $s_{x}^{2}$ and $s_{y}^{2}$ are sample variances of the volume.

We test the null hypothesis $H_{0}: \mu_{x}=\mu_{y}$ against the alternative hypothesis $H_{1}: \mu_{x}>\mu_{y}$ for each of the hypotheses postulated. Both t-statistics require the assumption of independence between two different samples. If $H_{0}$ is not rejected, we would conclude that the trading volume in 2001 is the same as that in 2000 and therefore there was no abnormal trading volume in the options markets. However, if $H_{0}$ is rejected, we would conclude that the volume in 2001 is significantly larger than 2000 and therefore do not reject the alternative hypotheses that abnormal trading volume related to the 9-11 attacks took place in the options markets in 2001. We use a one-sided test for all our hypotheses such that $H_{1}: \mu_{x}>\mu_{y}$ to test for the abnormal trading activities in 2001 as we believe that smaller volume in 2001 would mean that abnormal trading activities related to the 9-11 attacks were absent.

To test the Hypotheses P1-P2 and Hypotheses C1-C2, we study the volume for the test periods $T(n)$ for $n=1,2$ and 3, that is within 3 calendar months of the expiration of September contracts in both 2000 and $2001 .^{7}$ Rejection of these hypotheses on their own does not enable us to reject the null hypotheses that there was an absence of abnormal trading prior to the September 11 attacks, as the hyper-activities may be due to chronological effect or other factors. In order to validate the conclusion about insider effect drawn from the tests, that is to exclude the chronological effect, we study the mean volume during the control period $T(4+)$ which is the window starting from the first day of trading

7. $T(1)$ is from September 1 to September $21, T(2)$ is from August 1 to September 21, $T(3)$ is from July 1 to September 21. 
in the respective contracts until the end of June 2000 and 2001 respectively (That is 3 calendar months prior to September 2000 and 2001, respectively), as stated in Hypotheses P0 and C0. ${ }^{8}$ We further break up the test periods $T(n)$ for $n=1,2$ and 3 into sub-periods before September 11 - denoted as $T(n \mathrm{~A})$ - and sub-period from September 11 up to the contract expiration - denoted as $T(n \mathrm{~B})$, for $n=1,2$ and 3. ${ }^{9}$ Note that since $T(1 \mathrm{~B}), T(2 \mathrm{~B})$, and $T(3 \mathrm{~B})$ refer to the same sub-period, we shall denote this sub-period as $T$ (Post-9-11). If the mean volume during $T(4+)$ does not differ significantly between 2001 and 2000, while the mean volume during $T(n \mathrm{~A})[T(n \mathrm{~B})]$ for $n=1,2$ and 3 is significantly higher in 2001 than in 2000, we will not reject the alternative hypotheses that the pre-9-11 [post-9-11] abnormal activities are attributable to the 9-11 attacks.

To test the hypotheses V0-V2, we let $X_{1}, X_{2}, \ldots, X_{n_{x}}$ be the VIX observations with mean $\mu_{x}$, variance $\sigma_{x}^{2}$ and sample size $n_{x}$ for the period under study in 2001 and let $Y_{1}, Y_{2}, \ldots, Y_{n_{v}}$ be the VIX observations with mean $\mu_{y}$, variance $\sigma_{y}^{2}$ and sample size $n_{y}$ for the corresponding period in 2000. We then apply equations (1) or (2) for testing the hypotheses V0-V2. Similar to the test for P0-P2 and $\mathrm{C} 0-\mathrm{C} 2$, we study the VIX for the test periods $T(n)$ for $n=1,2$ and 3, that is within 3 calendar months before the September 11 both 2000 and $2001 .^{10}$ In order to minimize the chronological effect, we study the mean VIX during the control period $T$ ' (4+) which is 5 months from January 1 to June 10, 2000 and 2001 respectively (That is 3 calendar months prior to September 11, 2000 and 2001, respectively); and study the behavior of VIX in the Post 9-11 period by setting T(Post-9-11) be the period from September 11 to September 21 in both 2000 and 2001 to match with the Post 9-11 period studied for the call and put options. Different from the September option contracts ended at September 22, VIX does not have any expiry date. This allows us to study the behavior of VIX during the period after the expiry of the September option contract till the end of the year. Hence, we set $T$ '(Post-9-11) as the period from September 22

8. $T(4+)$ is from Jan 1 to June 30 .

9. $T(1 \mathrm{~A})$ is from September 1 to September $10, T(2 \mathrm{~A})$ is from August 1 to September $10, T(3 \mathrm{~A})$ is from July 1 to September 10 , and $T(n \mathrm{~B})$ is from September 11,2001 to September 21 for $n=1,2,3$.

10. $T^{\prime}(1)$ is from August 11 to September 10, T(2) is from July 11 to September 10, $T^{\prime}(3)$ is from June 11 to September 10, T'(4+) is from January 11 to June 10. 
to December 31, and test the behavior of VIX on $T$ (Post-9-11) between 2000 and 2001 for reference.

If the mean VIX during $T$ (4+) does not differ much between 2001 and 2000, while the means VIX during $T(n)$ for $n=1,2$ and 3 and during $T$ (Post-9-11) are significantly higher in 2001 than in 2000, we will not reject the alternative hypotheses that the pre-9-11 and the post-9-11 abnormal activities are attributable to the 9-11 attacks. However, there is no ground to support that the mean VIX in one year should be the same of the mean VIX in another year regardless of 9-11 event. In order to minimize the chronological effect and leave only the effect of 9-11 event, we employ the following statistics:

$$
T^{*}=\frac{\bar{X}-\bar{Y}-d}{s_{p} \sqrt{\frac{1}{n_{x}}+\frac{1}{n_{y}}}} \quad \text { or } \quad T^{*}=\frac{\bar{X}-\bar{Y}-d}{\sqrt{\frac{s_{x}^{2}}{n_{x}}+\frac{s_{y}^{2}}{n_{y}}}}
$$

to test for the periods $T^{\prime}(n)(n=1,2,3)$ and the period $T$ (Post-9-11) for the situations in which the hypothesis of equal variance is accepted or rejected respectively where $d$ is the mean difference of VIX in the period $T$ (4+) for 2001 and 2000.

The choice of statistics to be adopted in an event study is important. In this study we use the simple t-tests and nonparametric measures. Although they have their faults we deem them to be the better choice of faulty procedures. One of the procedures we rejected was Johnson's bootstrapped skewness-adjusted t-statistics. ${ }^{11}$ Computation-intensive bootstrapping-based statistics tests have been one of the methods widely studied to allay concern that early event studies were not as powerful and the models that contain specification problems. The resultant measure of statistical significance varies with each application of the same bootstrapped procedure applied to the same data due to sampling variation inherent in repeated random sampling. Consequently, researchers applying the same bootstrapped procedure on the same sample could conceivably reach contradictory conclusions.

The choice between alternative approaches for hypothesis testing hinges heavily on the power of a statistical test. Bootstrapping is mainly

11. For example see Sutton (1993), and Lyon, Barber and Tsai (1999)) and simulated empirical p-values used by Ikenberry et al (1995). 
used to deal with challenging situations when the sampling distribution of the test statistic is either indeterminate or difficult to obtain. A bootstrapping-based test is less powerful than other parametric or simple nonparametric tests when both are applicable. ${ }^{12}$ Eckbo et al. (2000) studied abnormal returns to holders of seasoned equity offerings and found that bootstrapping gives lower significance level relative to the Student's t-tests. In this paper, since our dataset is reasonably large and the inference is valid by virtue of the central limit theorem, hence we only employ the simple t-statistics and several non-parametric statistics to study the volume in options trading.

\section{Data and Findings}

The data on trading volume of the SPX index put and call options are obtained from Bloomberg with its selected characteristics tabulated in table 1. After excluding all inactive contracts, as well as contracts with bad data, the statistics of the most actively traded put options and the most actively traded call options are tabulated in table 2 . The difference in most actively traded contracts and least actively traded contracts easily range in several hundred times in terms of the order of magnitude. ${ }^{13}$ Table 2 reveals that trading volume increases as the contracts approach expiration, which is consistent with the findings in literature. ${ }^{14}$ The table also shows that the mean and the standard deviation of the trading volumes in September 2001 contracts were more than double those of September 2000 contracts during sub-period $T$ (1A) for both call and put, but not so much during the other sub-periods. This shows that there is extraordinary trading activity in the one-month period before 9-11.

We next investigate the distributions of volumes for the September 2000 and September 2001 put options and call options. Tables 3A and $3 \mathrm{~B}$ profile the cumulative frequency distributions of volumes and the total number of contracts for the September 2000 and September 2001

12. For example see Efron and Tibshirani (1993) and Davison and Hinkley (1997).

13. We only list in the tables for the most actively traded contracts and do not report the least actively traded contracts which are available on request.

14. See for example Stoll and Whaley (1991). 
TABLE 1. Selected Sample Characteristics for Sept 2000 and Sept 2001 SPX Index Options Contracts

\begin{tabular}{lcc}
\hline & $\begin{array}{c}\text { Sept 2000 SPX Index } \\
\text { Options Contracts }\end{array}$ & $\begin{array}{c}\text { Sept 2001 SPX Index } \\
\text { Options Contracts }\end{array}$ \\
\hline $\begin{array}{l}\text { S\&P 500 index closing } \\
\text { price on last trading date }\end{array}$ & 1480.87 & 984.54 \\
\hline $\begin{array}{l}\text { S\&P 500 index moving } \\
\text { average within 28 days } \\
\text { before the last trading day } \\
\text { (MA28) }\end{array}$ & 1495.78 & 1120.00 \\
\hline $\begin{array}{l}\text { Highest strike price } \\
\text { Lowest strike price }\end{array}$ & 1640 & 1370 \\
\hline $\begin{array}{l}\text { Number of strike prices } \\
\text { within the range (in } \\
\text { increments of 10) }\end{array}$ & 1300 & 860 \\
$\begin{array}{l}\text { Inactive put options \& put } \\
\text { options with bad data }\end{array}$ & 35 & 20 \\
$\begin{array}{l}\text { Inactive call options \& call } \\
\text { options with bad data }\end{array}$ & 22 & 23 \\
\hline
\end{tabular}

Note: This table lists some important figures for Sept 2000 and Sept 2001 SPX Index Options Contracts for comparison.

put options and call options, respectively, while figure 2 exhibits the corresponding probability distributions by juxtaposing the frequencies contracts for volumes of the September 2000 and September 2001 put options and call options at three levels of moneyness (OTM, ATM and ITM). The distribution in 2001 is also profiled by normalizing the total volume in 2000 as $100 \%$ for easy comparison purpose. In addition, tables 4A and 4B report the top-ten extreme observations for the September 2000 and September 2001 put options and call options, respectively, by the three levels of moneyness.

Table 3A and figure 2A show that the September 2001 put options distributions and the September 2000 put options distributions are similar in that their respective modes are well under 5 volumes per contract, but differ in that the former have higher frequencies in the range between 5 to 50 volumes and in the extreme values at all levels of moneyness. All the three pairs of distributions have lower quartiles under 5 volumes per contract and medians in the low teens; OTM options and ATM options distributions have upper quartiles slightly 
TABLE 2. Most Actively Traded SPX Index Put and Call Options

\begin{tabular}{ccc}
\hline & \multicolumn{2}{c}{ Strike price (Average volume / S.D. $)$} \\
\cline { 2 - 3 } Sub-period & $\begin{array}{c}\text { Sept } 2000 \text { SPX Index } \\
\text { Put Options }\end{array}$ & $\begin{array}{c}\text { Sept 2001 SPX Index } \\
\text { Put Options }\end{array}$ \\
\hline Overall & $1400(181.6 / 380.8)$ & $980(303.9 / 522.4)$ \\
$T(4+)$ & $1440(115.7 / 231.8)$ & $1080(200.0 / 0)$ \\
$T(3)$ & $1400(403.1 / 577.1)$ & $1150(409.8 / 977.7)$ \\
$T(2)$ & $1400(507.9 / 618.1)$ & $1000(388.7 / 704.3)$ \\
$T(1)$ & $1450(550.6 / 340.4)$ & $1080(932.3 / 1653.9)$ \\
$T(3 \mathrm{~A})$ & $1400(414.2 / 598.2)$ & $1150(442.6 / 1010.5)$ \\
$T(2 \mathrm{~A})$ & $1400(545.7 / 653.2)$ & $1150(388.9 / 806.3)$ \\
$T(1 \mathrm{~A})$ & $1400(714.2 / 774.9)$ & $1110(1497.2 / 1612.8)$ \\
\hline Sub-period & Sept 2000 SPX Index & Sept $2001 \mathrm{SPX}$ Index \\
& Call Options & Call Options \\
\hline Overall & $1560(240.9 / 522.9)$ & $1260(317.6 / 992.8)$ \\
$T(4+)$ & $1540(63.8 / 112.2)$ & $1220(37.0 / 70.6)$ \\
$T(3)$ & $1560(331.4 / 604.6)$ & $1260(411.1 / 1121.9)$ \\
$T(2)$ & $1510(373.6 / 706.2)$ & $1260(407.0 / 950.3)$ \\
$T(1)$ & $1520(725.2 / 855.1)$ & $1150(530.6 / 508.0)$ \\
$T(3 \mathrm{~A})$ & $1560(355.7 / 625.4)$ & $1260(411.1 / 1121.9)$ \\
$T(2 \mathrm{~A})$ & $1560(371.0 / 663.8)$ & $1220(729.3 / 796.1)$ \\
$T(1 \mathrm{~A})$ & $1520(334.8 / 245.5)$ & \\
\hline
\end{tabular}

Note: This table lists strike price, average volume per contract and its standard deviation for Sept 2000 and Sept 2001 SPX Index Options (put and call) Contracts for each sub-period for comparison. Refer to footnote 8 [10] for the definitions of $T(n)[T(n \mathrm{~A})]$ for $n=1,2$ and 3 ; and refer to footnote 9 for the definition of $T(4+)$.

over 50 volumes per contract, while ITM options distributions have upper quartiles slightly over 20 volumes per contract. The higher frequency of extreme values in the September 2001 distribution may be an indication of more active speculative activities during 2001.

We further investigate the extreme observations and list the top-ten extreme observations for the September 2000 and September 2001 put options in table 4A and figure $3 \mathrm{~A}$. From table 4A, we find that all the top-ten extreme volumes for the September 2001 put options are much higher than their September 2000 counterparts. Most of the top-ten extreme volumes in the September 2001 put options occurred prior the 9-11 attacks. For the September 2001 OTM put options, two extreme volumes occurred on September 10, and one on September 6 and September 4 each; for the September 2001 ATM put options, extreme volumes are observed on September 6, September 4, August 31, and 

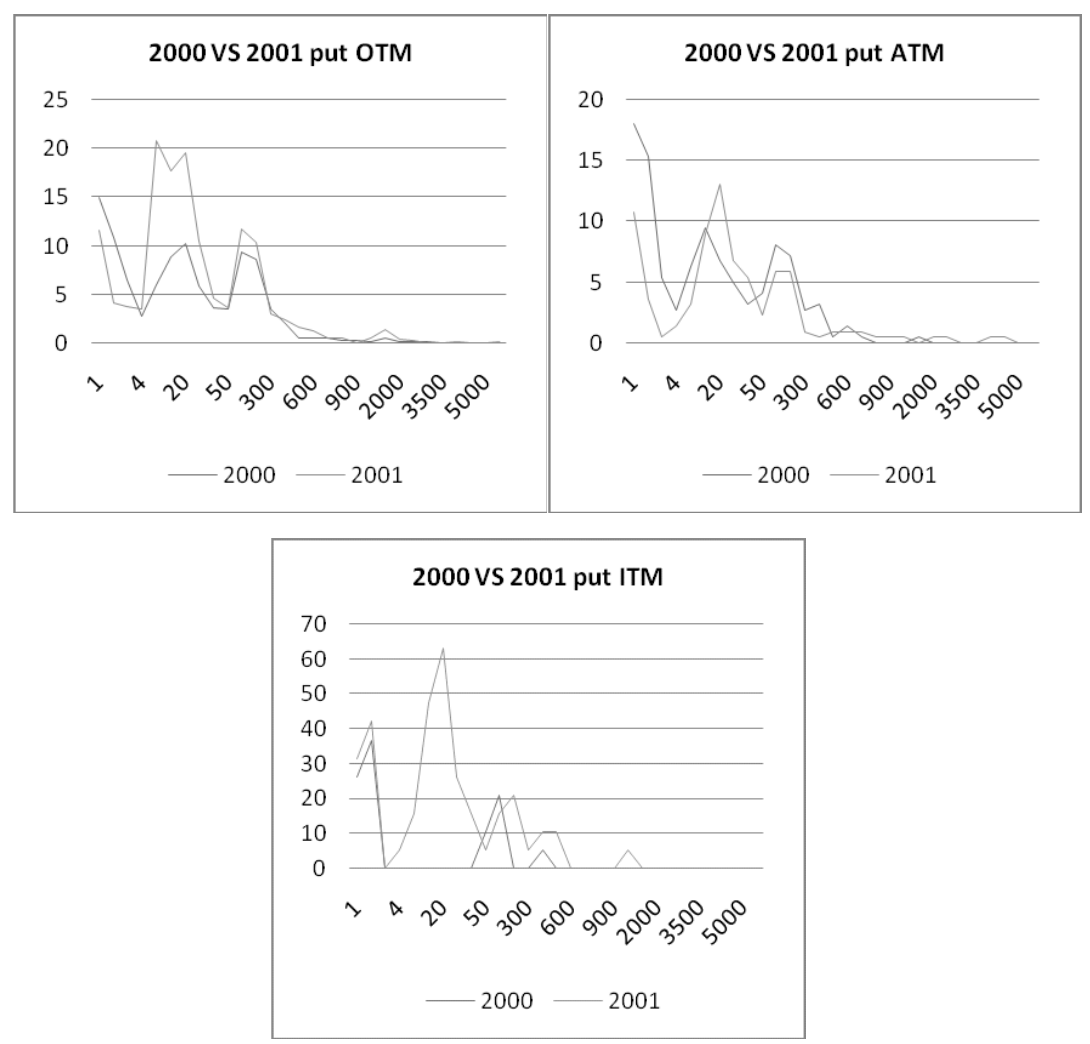

FIGURE 2A.- Frequency Distributions of Volumes for September 2000 and September 2001 OTM, ATM and ITM Put Options (January 1 to September 11)

Note: The charts plot the frequency distributions of volumes for Sept 2000 and Sept 2001 put options. The 2001 distribution is plotted by adjusted by the ratio of the total numbers of contracts in 2001 and 2000 while the 2000 distribution is plotted by setting its total cumulative frequency distribution for volumes to be $100 \%$.

August 28; for September 2001 ITM put options, extreme volumes are observed on September 7, September 6, September 5 and August 30. As these trades took place only a few days prior to the 9-11 attacks, they probably provide some supports to the claims by some quarters that insiders tried to profiteer from the options market in anticipation of the 9-11 attacks. In addition, we find in table 4A that the top extreme volume of 5,243 in OTM September 2001 put options occurred on July 31 , which could be used as further evidence to support the claim that 


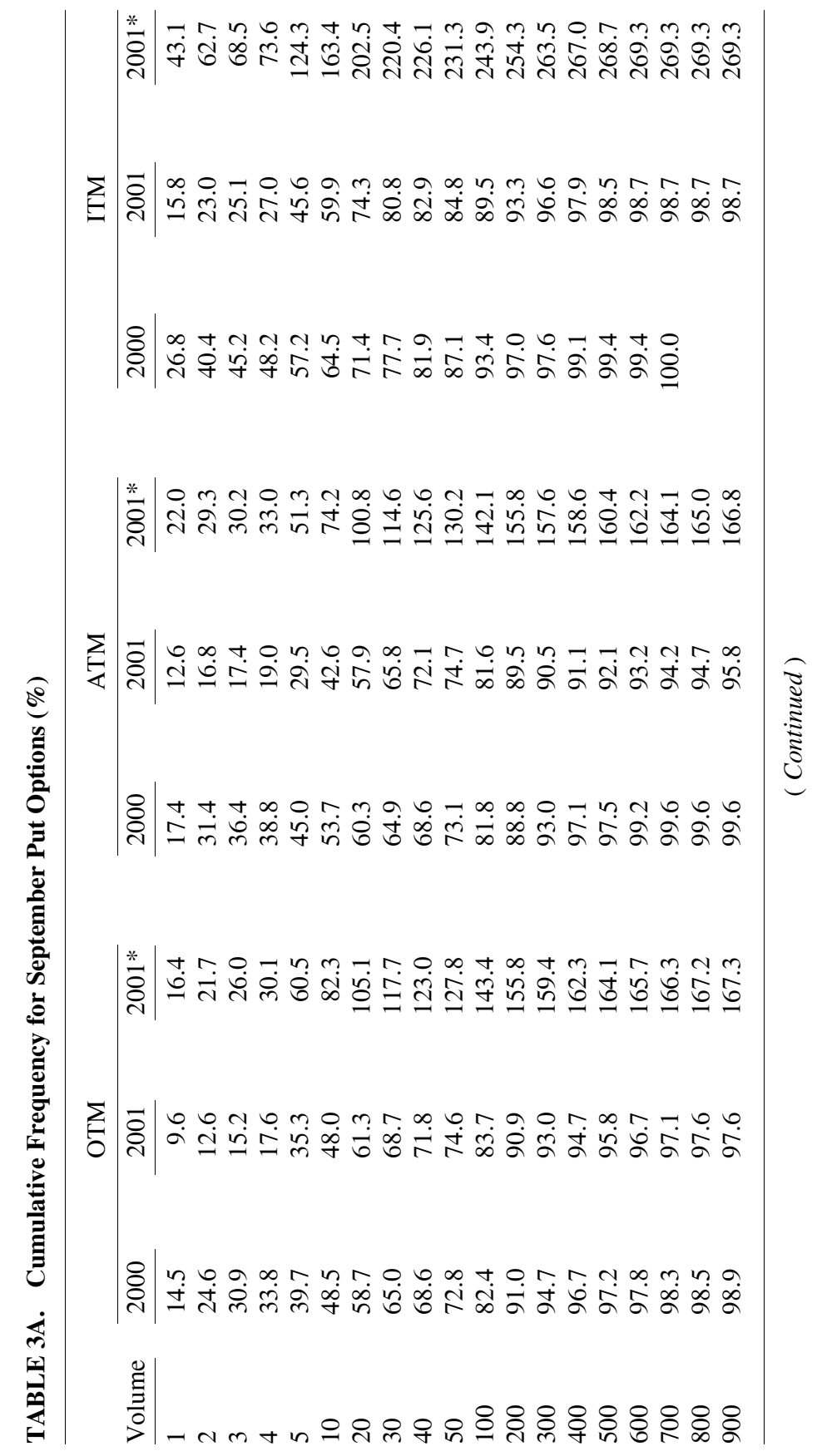




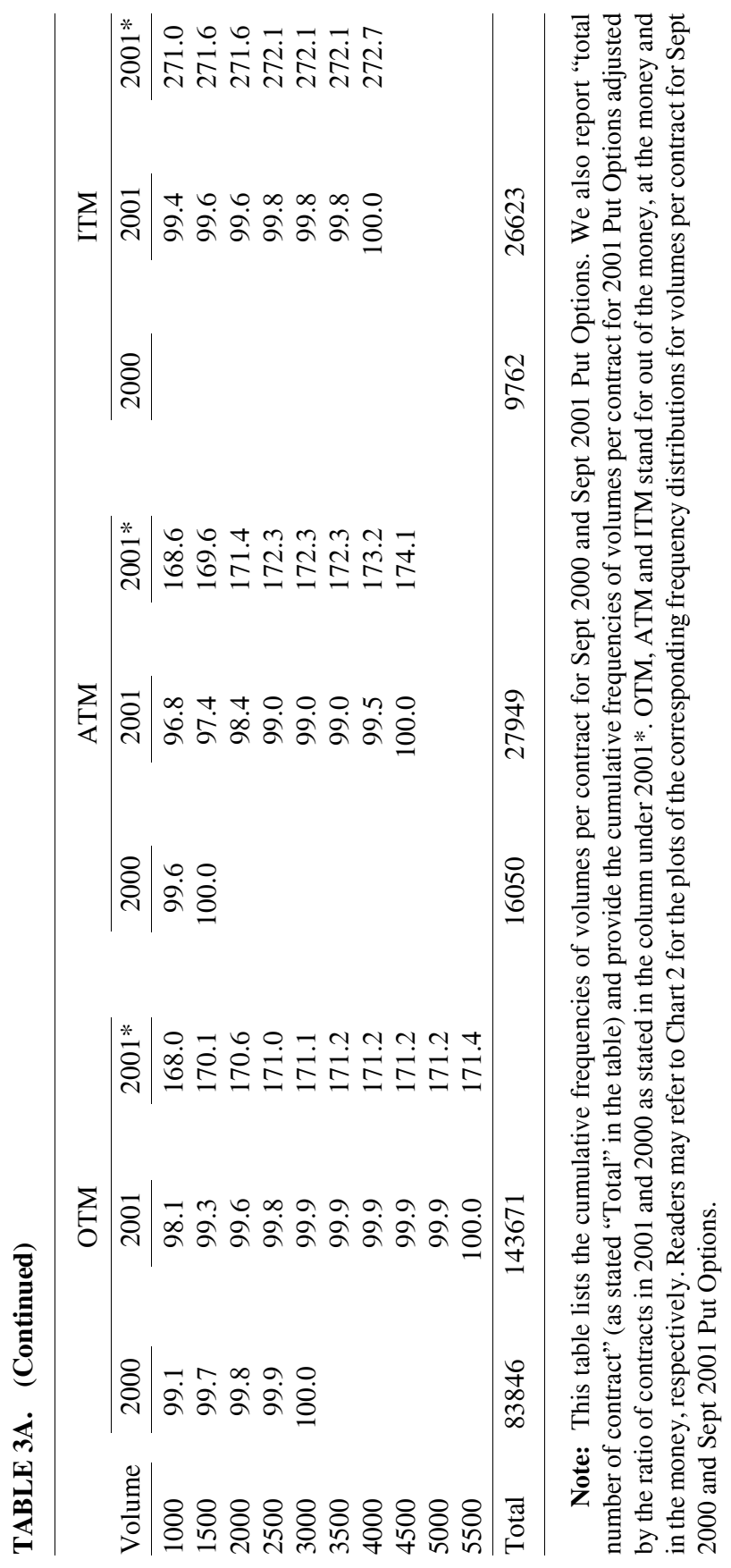


*

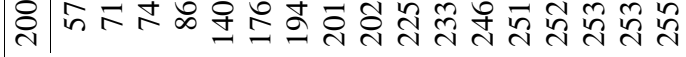

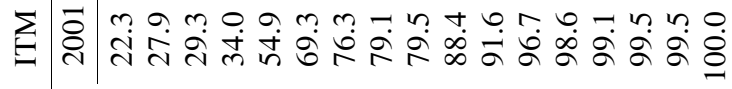

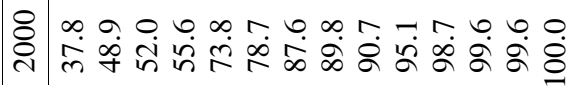

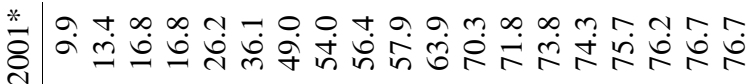

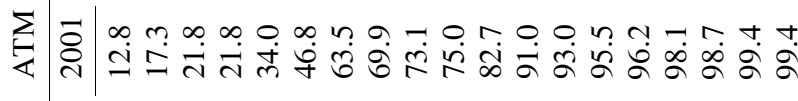

吾

*

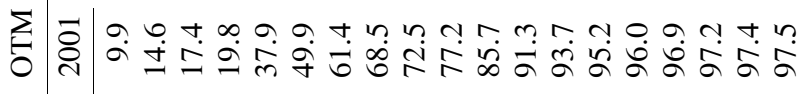

$8 \infty-m-0$ m n

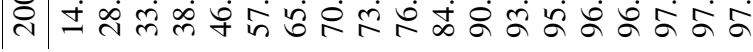




\section{Abnormal Option Trading}

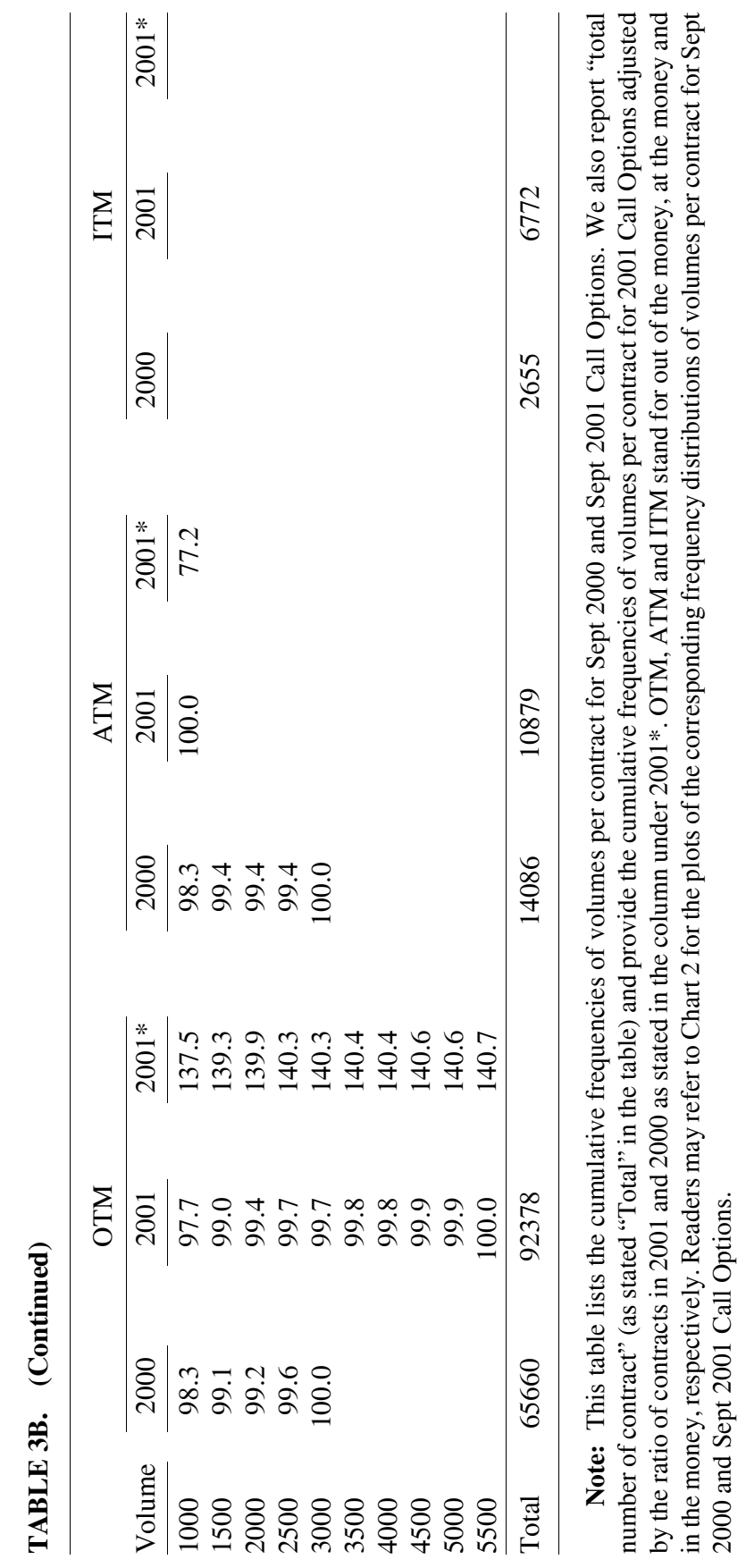




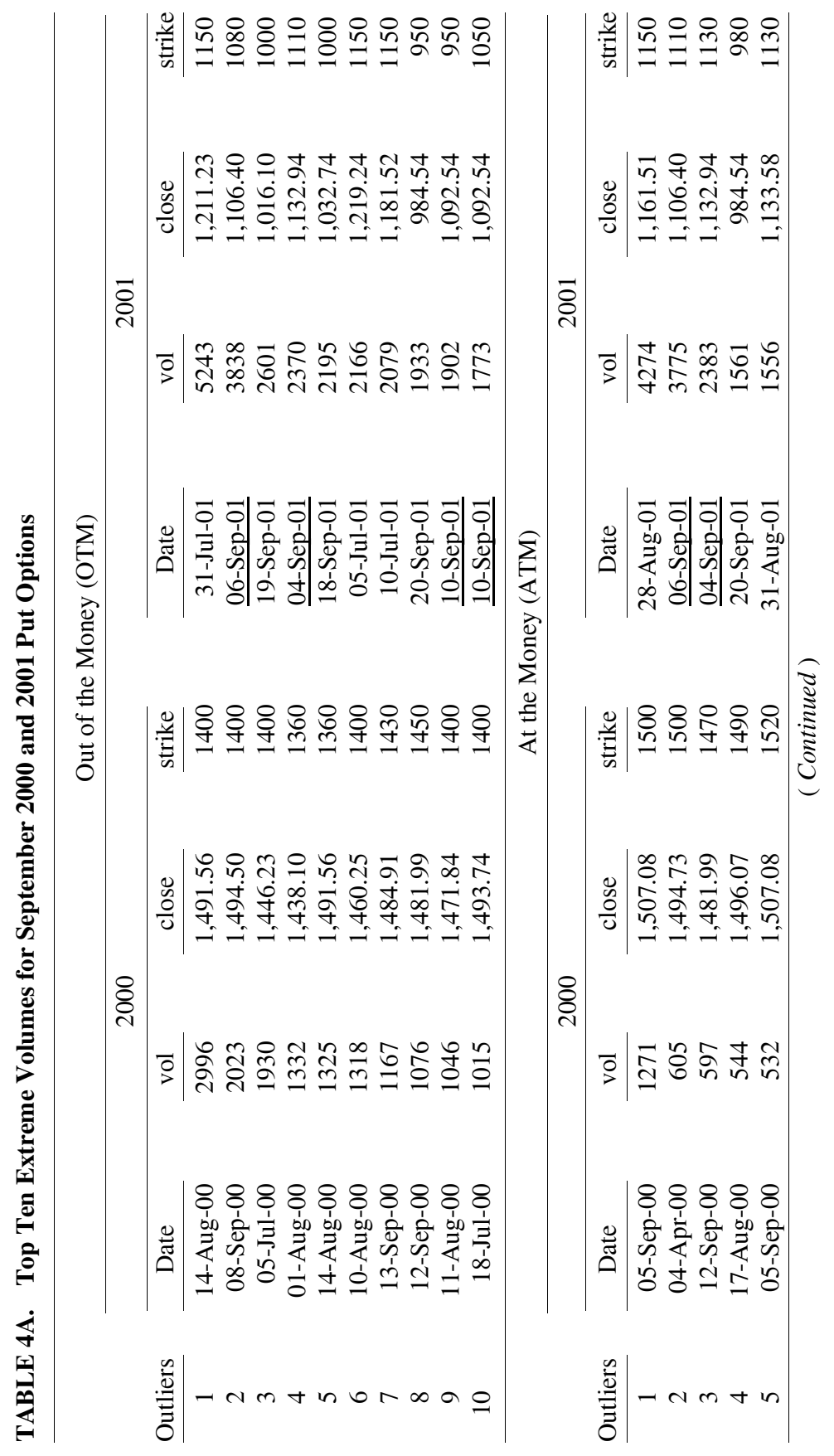




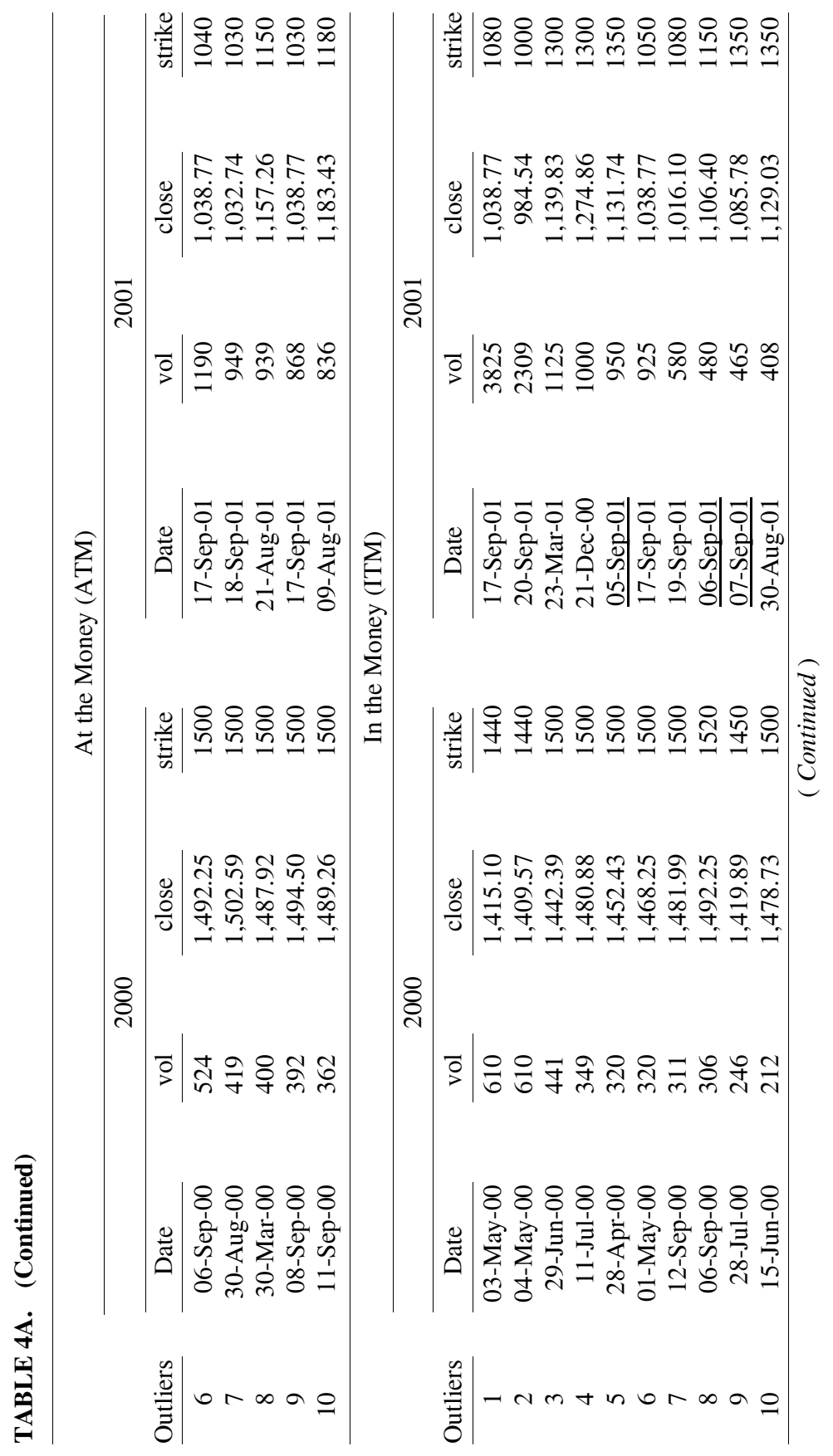




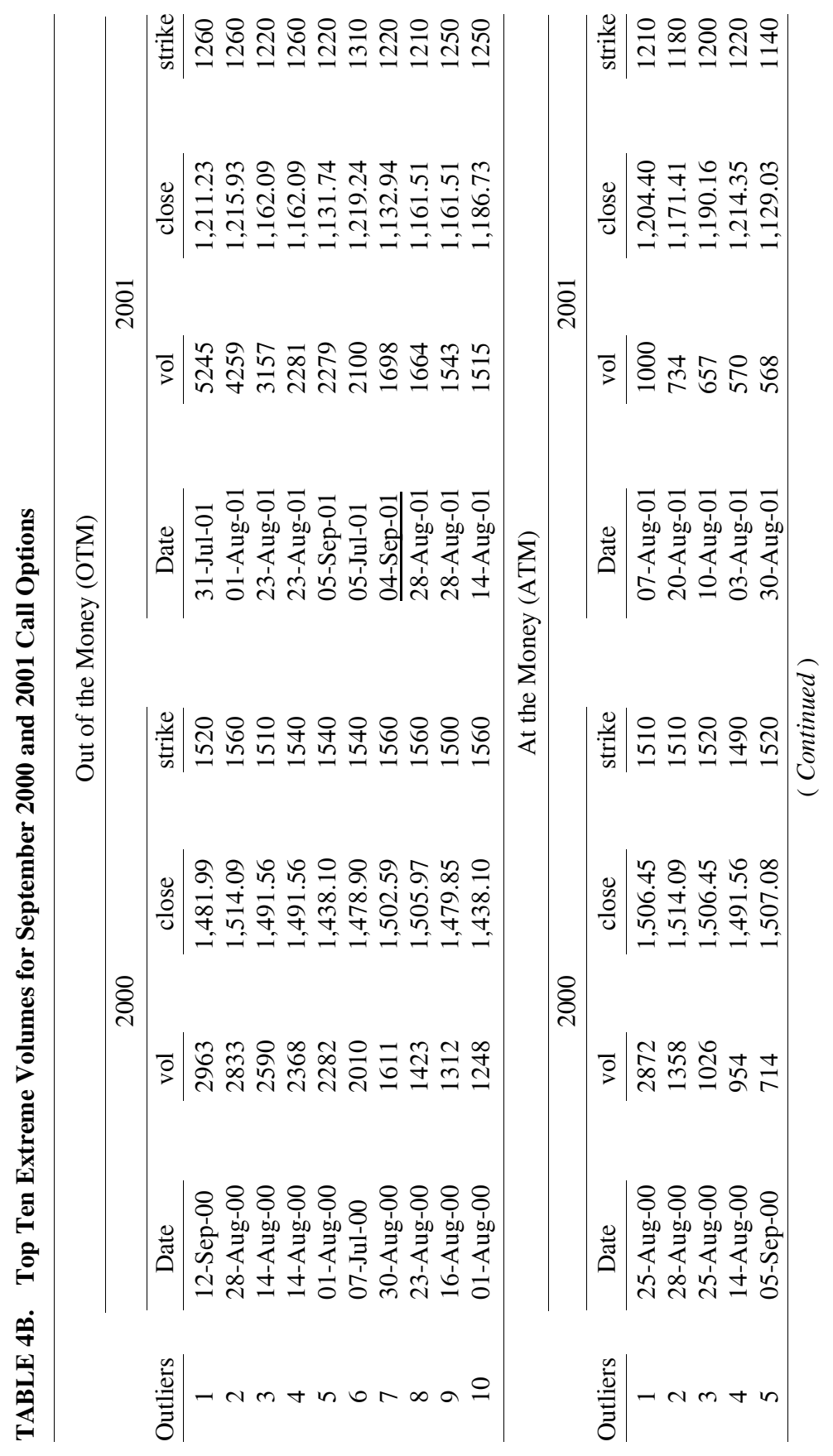




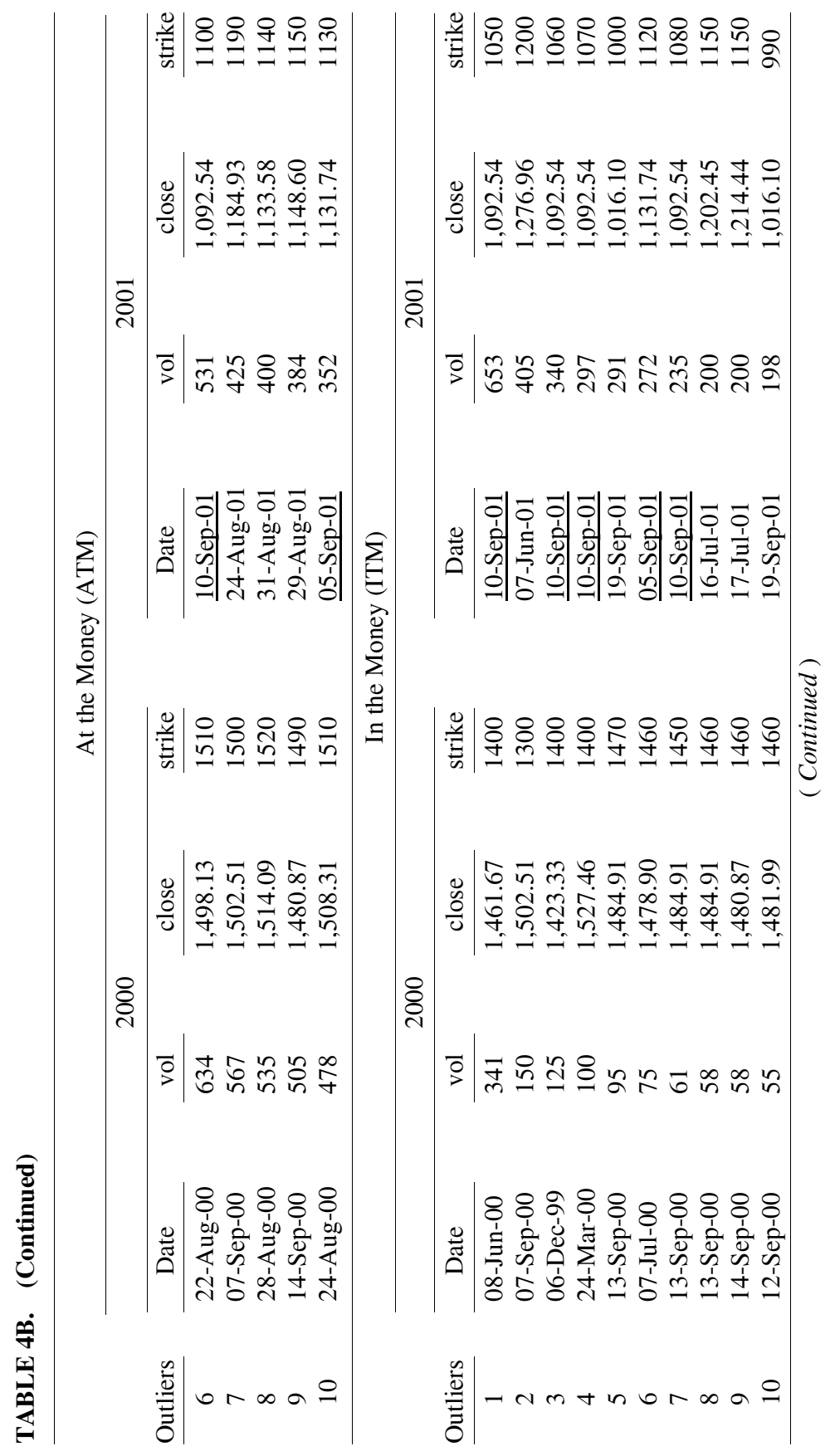




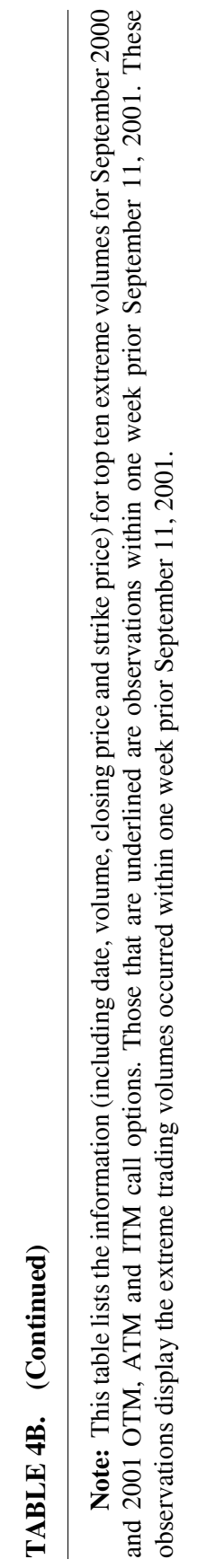




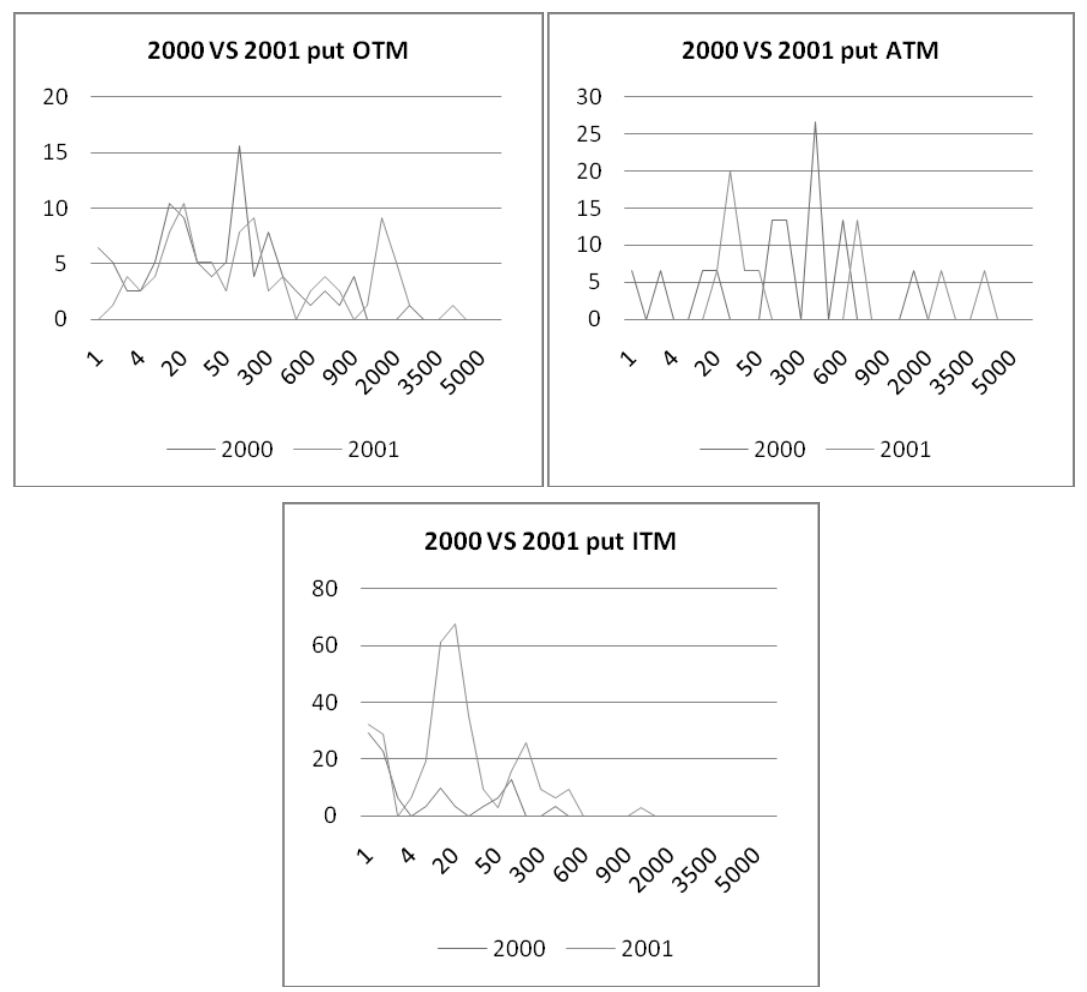

FIGURE 3A.-Frequency Distributions of Volumes for September 2000 and September 2001 OTM, ATM and ITM Put Options (10 Trading Days to September 11)

Note: The charts plot the frequency distributions of volumes for Sept 2000 and Sept 2001 put options from 10 trading days to September 10 . The 2001 distribution is plotted by adjusted by the ratio of the total numbers of contracts in 2001 and 2000 while the 2000 distribution is plotted by setting its total cumulative frequency distribution for volumes to be $100 \%$.

some insiders who might know something would be happening but had no knowledge of the exact date of the event. Consistent with the findings from table $3 \mathrm{~A}$, figure $3 \mathrm{~A}$ show that there are some extreme volumes trading in OTM, ATM and ITM September 2001 put options. We note that figure $3 \mathrm{~A}$ also show that there are extremely volumes of contract not only trading large volumes per contract but also in any contract more than 5 volumes with the mode of frequency to be at 20 . This shows that, if there exists any inside trader, instead of trading 

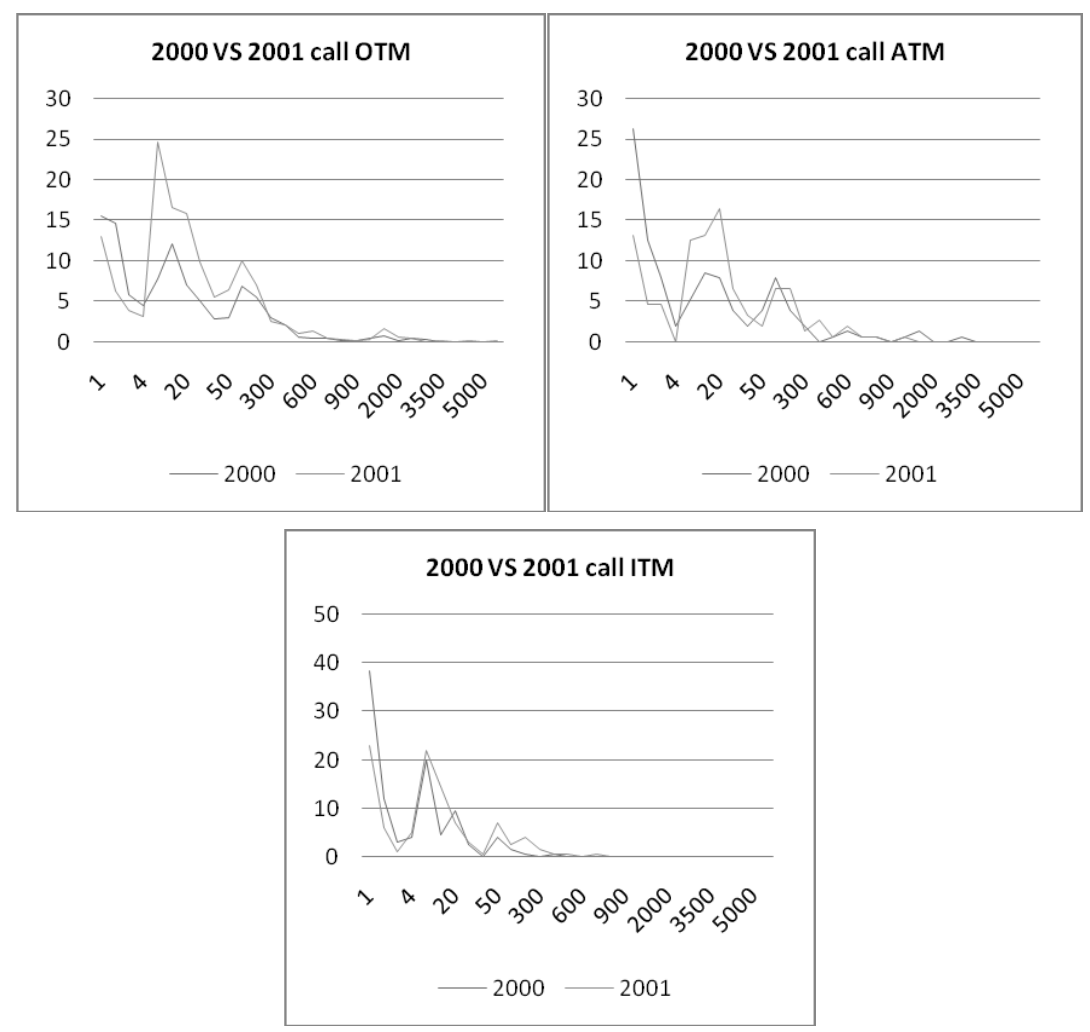

FIGURE 2B.-Frequency Distributions of Volumes for September 2000 and September 2001 OTM, ATM and ITM Call Options (January 1 to September 11)

Note: The charts plot the frequency distributions of volumes for Sept 2000 and Sept 2001 call options. The 2001 distribution is plotted by adjusted by the ratio of the total numbers of contracts in 2001 and 2000 while the 2000 distribution is plotted by setting its total cumulative frequency distribution for volumes to be $100 \%$.

extreme volume in each contract, they could trade large number of contracts on not too extreme volume per contract.

Table $3 \mathrm{~B}$ and figure $2 \mathrm{~B}$ show that the three pairs of distributions for call options display similarities with their put counterparts, that is lower quartiles under 5 volumes per contract, medians in the low teens, upper quartiles slightly over 50 volumes per contract for OTM options and ATM options, and upper quartiles slightly over 20 volumes per contract 


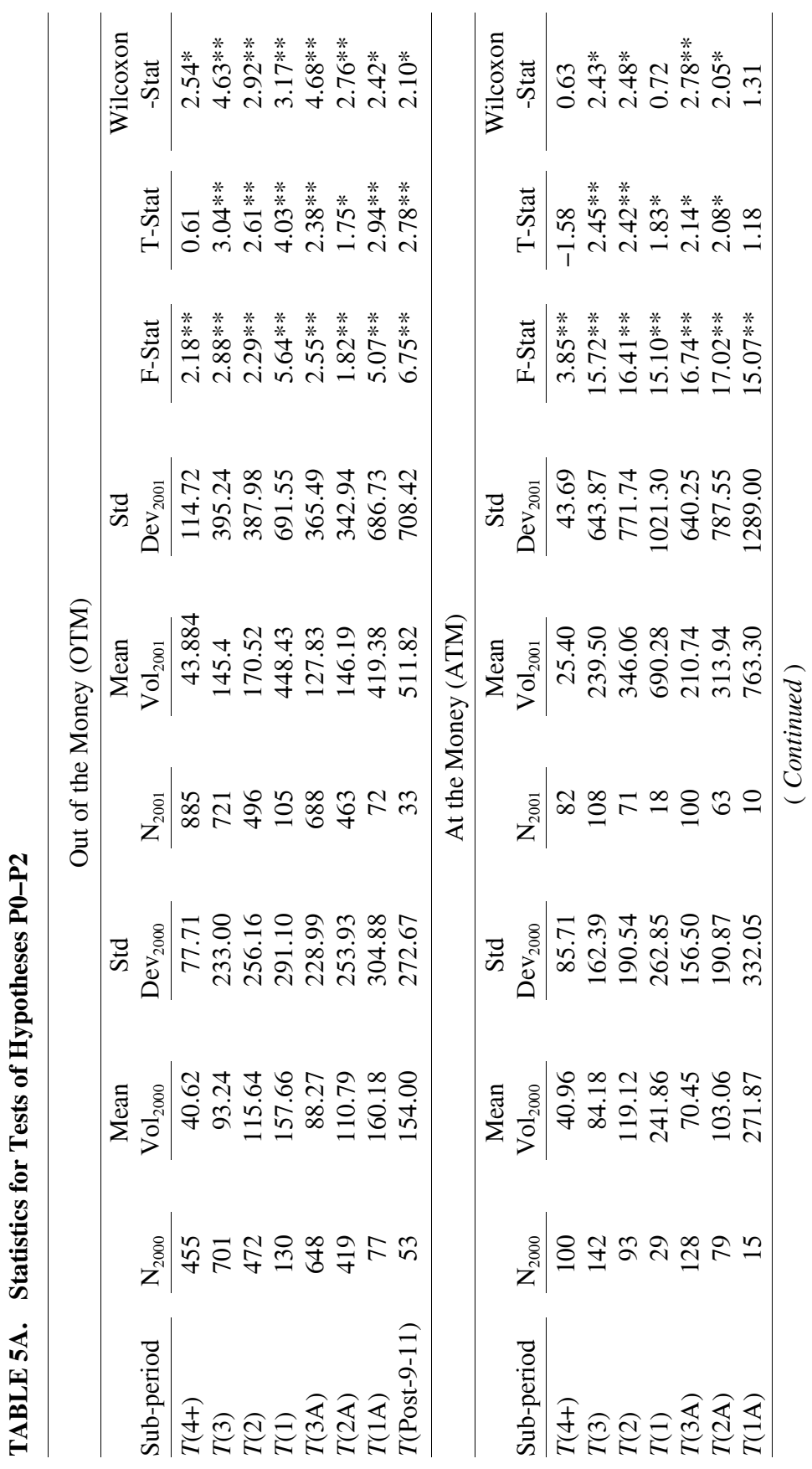




\section{Abnormal Option Trading}

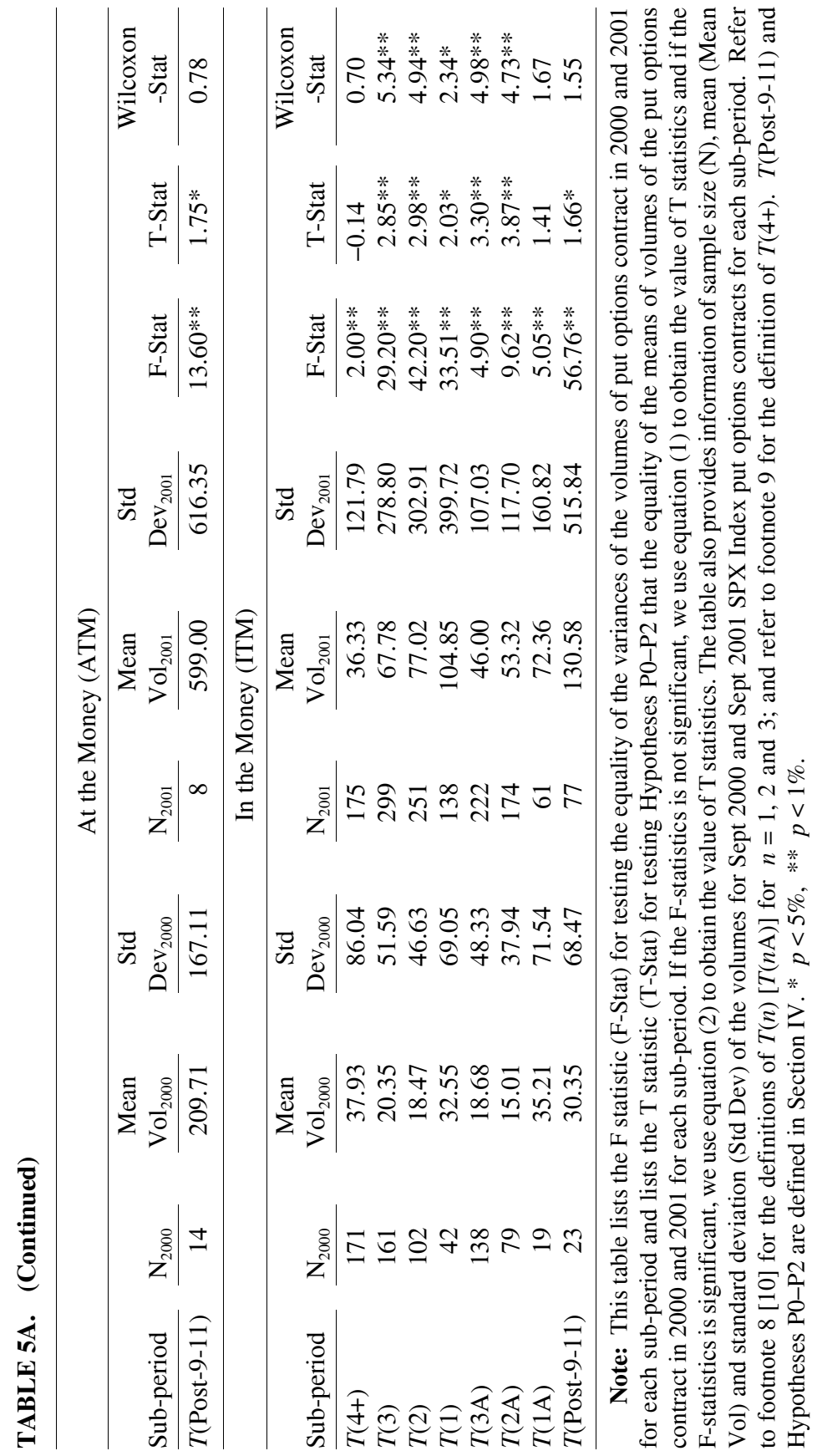



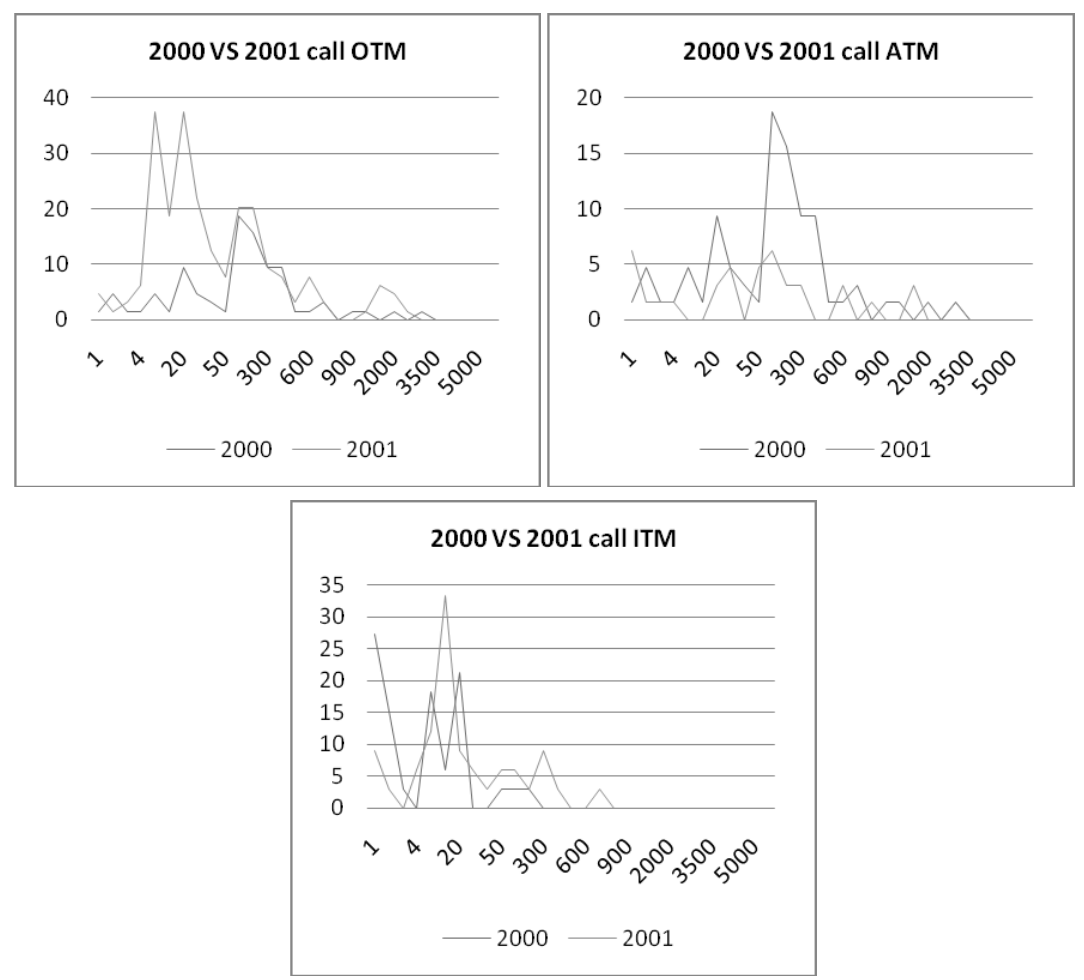

FIGURE 3B.-Frequency Distributions of Volumes for September 2000 and September 2001 OTM, ATM and ITM Call Options (10 Trading Days to September 11)

Note: The charts plot the frequency distributions of volumes for Sept 2000 and Sept 2001 call options from 10 trading days to September 10 . The 2001 distribution is plotted by adjusted by the ratio of the total numbers of contracts in 2001 and 2000 while the 2000 distribution is plotted by setting its total cumulative frequency distribution for volumes to be $100 \%$.

for ITM options. However, unlike their put counterparts, the extraordinary activities in the call options are not so apparent since the September 2001 OTM and ITM call options display more extreme volumes compared to their September 2000 counterparts, but the reverse is true for the ATM call options. In addition, the extreme volumes of ITM call options are comparatively smaller. Nonetheless, the higher frequency of extreme volumes per contract in the September 2001 OTM and ITM (especially the former) may also be an indication of more active speculative activities during 2001. In table 4B, we find that all the 
top-ten extreme volumes for the ITM call options are much higher for the September 2001 contracts than those of September 2000. Similar to the put options, most of the extreme volumes in call options took place prior the 9-11 attacks. The findings from figure 3B are consistent with those from table 4B.

In table 5A, all the F-statistics are significant at the $1 \%$ level, that is unequal variance of 2001 sample trading volume compared to variance of 2000 sample trading volume or $\sigma_{x}^{2} \neq \sigma_{y}^{2}$. Therefore, all t-statistics were based on unequal variance, that is equation (2). We find that the trading volume for the SPX index put options during the control periods $T(4+)$ is not significantly different between 2001 and 2000 for OTM, ATM and ITM contracts. On the basis of these results, we do not reject the Hypothesis P0 and conclude that there is no evidence of abnormal trading in September 2001 OTM SPX index put options during the window extending from first day of trading up to 3 calendar months prior to the 9-11 attacks. This is an important result revealing the consistency with the years 2000 and 2001 being similar in regard to option activity in a time period before intense trading began in September index put options. This result is in line with our ex ante expectation that speculators are unlikely to dabble in far term contracts.

We now look into the trading volume of the September 2001 and September 2000 SPX index put options in the periods closer to 9-11, that is $T(n)$ for $n=1,2$ and 3 for OTM, ATM and ITM contacts. From table 5A, we first find that all the t-statistics are significantly greater than zero. We further find that the difference in trading volume is significant for OTM put during $T(n \mathrm{~A})$ for all $n=1,2,3$, and significant for ATM and ITM September 2001 SPX index put options during $T(2 \mathrm{~A})$ and $T(3 \mathrm{~A})$. These results lead us to reject Hypothesis P1 that the mean trading volume in September 2001 (short term) OTM, ATM and ITM SPX index put options prior to the 9-11 attacks does not differ from normal mean trading volume of OTM SPX index put options. From the definitions of $T(n)$ and $T(n \mathrm{~A})$ for $n=1,2$ and 3, the above results lead us conclude that there is evidence of abnormal trading in the September 2001 OTM, ATM and ITM SPX index put options within the immediate window of up to 3 calendar months prior to the 9-11 attacks.

The results on $T$ (Post-9-11) from table $5 \mathrm{~A}$ also show that abnormal trading in September 2001 OTM, ATM and ITM SPX index put options carried on post-9-11 attacks. On the basis of these results, we reject Hypotheses P2, and conclude that there is also evidence of abnormal trading in the September 2001 OTM, ATM and ITM SPX index put 


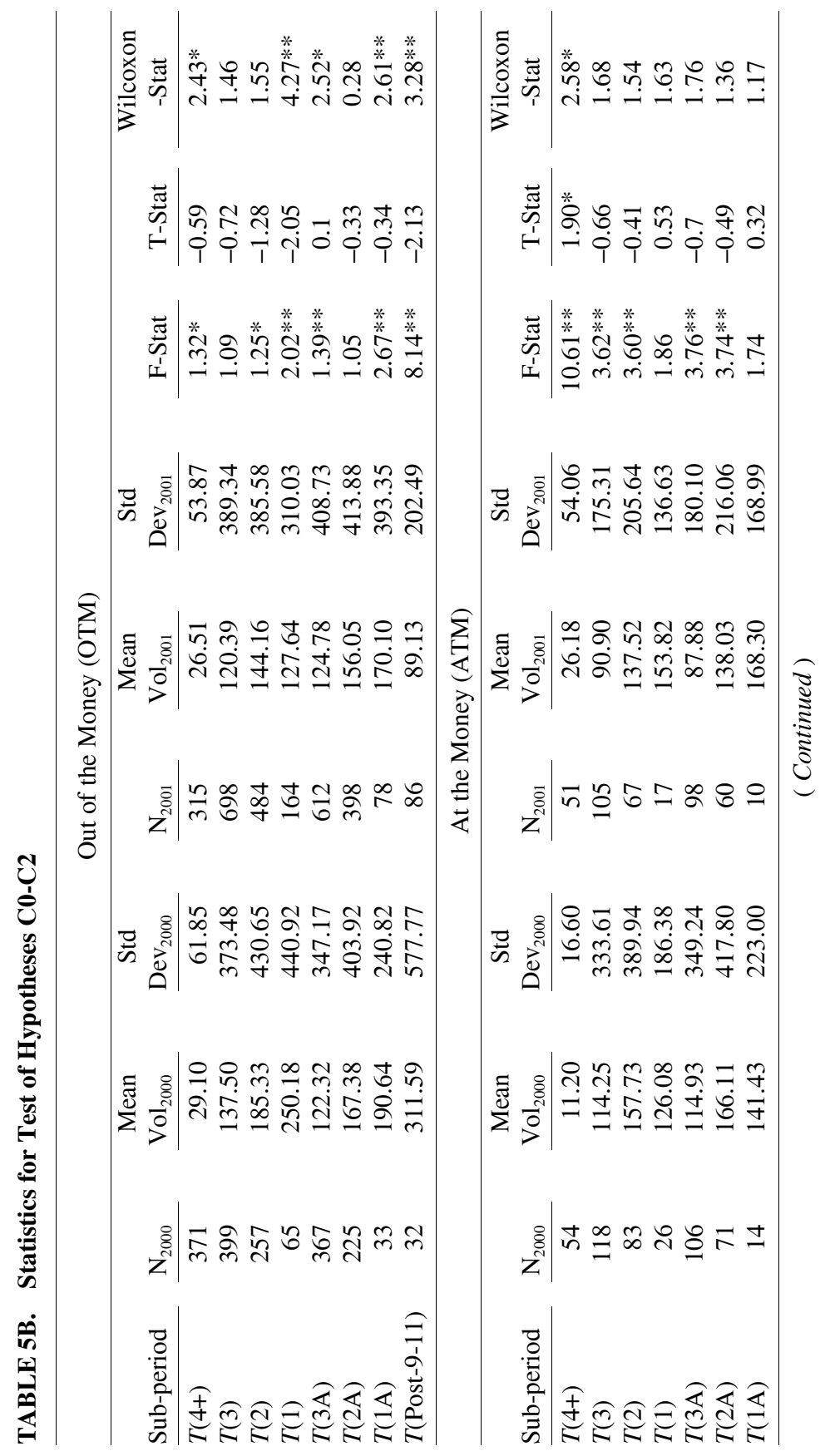




\section{Abnormal Option Trading}

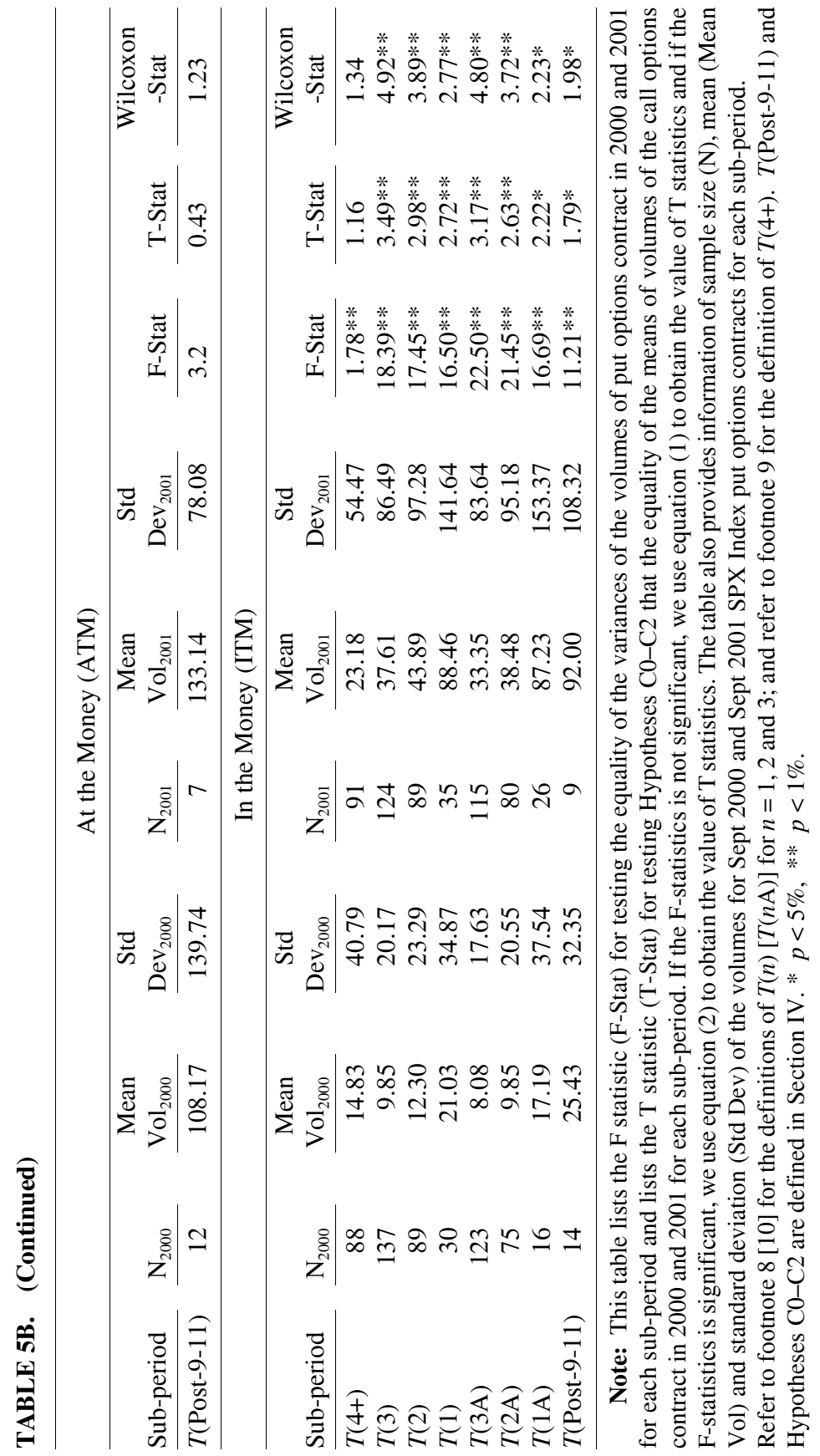


options immediately after the 9-11 attacks. We note that the abnormal trading after the attacks would be expected given that those with positions would be trying to protect themselves from lower markets after the catastrophe.

These results are consistent with the trading strategies which we outlined in section III. If insiders were indeed active in the market, those who initially anticipated moderate decline in the equity market probably changed their views about the severity of the impending impacts of the 9-11 attacks during the month of September 2001 - that is as the attacks became imminent - and therefore switched or terminated their earlier strategies of speculating using ITM and/or ATM September 2001 SPX index put options, abnormal trading volume would be observed during $T(2 \mathrm{~A})$ and $T(3 \mathrm{~A})$, but this would disappear during $T(1 \mathrm{~A})$. Another possible explanation is that some insiders who might know something would be happening but had no knowledge of the exact date of the event. Post-facto, the results during T(Post-9-11) are consistent with the fact that the equity market slipped dramatically post-9-11 attacks.

We also deduce that the abnormal trading in the September 2001 OTM and ITM SPX index put options during the window of the second and third months prior to the 9-11 attacks - that is during $T(3 \mathrm{~A})$ and $T(2 \mathrm{~A})$ - is consistent with the Put Bear Spread strategy. We further deduce that the lack of abnormal trading in ITM SPX index put options during $T(1 \mathrm{~A})$ (in contrast to evidence of abnormal trading in OTM SPX index put options during the same period) is consistent with the deployment of Put Purchase strategy using OTM SPX index put options. To state our results simply, we find no evidence of increased volume of OTM put options trading more than 3 calendar months before September 11, 2001, but as September 11, 2001 approached, this changed with evidence of increased volume beyond the normal level.

We now turn to study the activities at the SPX index call options. Table 5B summarizes the results of testing for Hypotheses $\mathrm{C} 0-\mathrm{C} 2$. The t-statistic in the table shows that during $T(4+)$, the trading volume is not significantly different between September 2001 and September 2000 OTM and ITM SPX index call options, but marginally significant for ATM call options during the control period. This leads us to conclude that the lack of abnormal trading in September 2001 compared with September 2000 OTM and ITM SPX index call options during the control period is consistent with our ex ante expectation about speculators' behaviors, while the observed abnormal trading in September 2001 ATM SPX index call options compared to their 
September 2000 counterparts is probably due to increased market volatility as we observed through the Bollinger Bands.

We next look into the trading volume of the September 2001 and September 2000 SPX index call options in the periods of interest $T(n)$ for $n=1,2$ and 3 for OTM, ATM and ITM contacts. We are unable to reject the OTM and ATM components in Hypotheses C1 and C2 (That is insofar as the hypotheses pertain to OTM and ATM call), and conclude that during the three months preceding the 9-11 attacks, there is no abnormal trading in September 2001 SPX index OTM and ATM call options. This means that we are unable to draw any inference regarding the use of the Synthetic Short Sale strategy or the Naked Call Write of OTM and ATM call strategy prior to the 9-11 attacks.

Table 5B also shows that there are significant increases in trading volumes in the ITM SPX index call options during the testing periods, including both the pre-9-11 attacks and the post-9-11 attacks sub-periods. We therefore reject the ITM component of Hypotheses C1 and $\mathrm{C} 2$ and conclude that during the three months preceding the 9-11 attacks, there is abnormal trading in September 2001 SPX index ITM call options. This is consistent with the hypothesis that well-endowed speculators employed the Naked Call Write of ITM call strategy prior to the 9-11 attacks.

We now verify the results by using the VIX index. The statistics in table 6 reject the equality of variance for VIX in 2000 and 2001 for all testing periods and show that VIX has higher means in 2001 for all testing periods in our study, with the smallest difference in means for 2001 in the period $T(4+)$. To eliminate the effect of the mean VIX far before the 9-11 attacks, we employ the $T^{*}$ statistics in (3) for the testing. Nevertheless, the results still lead us reject Hypotheses V1 and V2 and conclude that the mean for VIX is significant higher in any of the 3-month periods prior to the 9-11 attack and the period, $T$ (Post-911), in the post 9-11 attack but not during the period, $T$ '(4+), far before 9-11 nor during the period, $T$ '(Post-911), far after the 9-11..$^{15}$

The results using the VIX are subject to an alternative explanation. That is, the trading volume in options during the 2001 period is the result of expectations that variance will be greater than it was in 2000 . High variability of the underlying asset makes the options worth more

15. We note that we also study the behavior of VIX on other partitions, for example, on every month before 9-11 and each month after 9-11. The results (available on request) are basically consistent of the reported results that VIX differs mainly on the 3 months prior to 9-11 and about 1 month after 9-11. 
TABLE 6. Statistics for Test of Hypotheses V0-V2

\begin{tabular}{|c|c|c|c|c|}
\hline Sub-period & F-Stat & T-Stat & $\mathrm{T}^{*}$-Stat & Wilcoxon-Stat \\
\hline$T(1)$ & $12.00 * * *$ & $7.63 * * *$ & $5.68 * * *$ & $5.34 * * *$ \\
\hline$T^{\prime}(2)$ & $3.75 * * *$ & $8.79 * * *$ & $5.39 * * *$ & $7.36 * * *$ \\
\hline$T^{\prime}(3)$ & $2.22 * * *$ & $7.06 * * *$ & $2.98 * * *$ & $6.49 * * *$ \\
\hline$T(4+)$ & $1.86^{* * *}$ & $3.15 * * *$ & 0.00 & $3.35 * * *$ \\
\hline$T$ (Post-9-11) & $8.87 * * *$ & $17.44 * * *$ & $16.22 * * *$ & $2.93 * *$ \\
\hline$T^{\prime}($ Post-9-11) & $2.85 * * *$ & $1.88 *$ & -0.44 & 1.15 \\
\hline
\end{tabular}

Note: This table lists the F statistic (F-Stat) for testing the equality of the variances of the CBOE VIX in 2000 and 2001 for each sub-period and lists the T statistic (T-Stat) for testing Hypotheses V0-V2 that the equality of the means VIX in 2000 and 2001 for each sub-period. If the F-statistics is not significant, we use equation (3) to obtain the value of T statistics and if the F-statistics is significant, we use equation (3A) to obtain the value of $\mathrm{T}$ statistics. Refer to footnote 11 for the definitions of $T^{\prime}(n)$ for $n=1,2$ and 3; and $T^{\prime}(4+)$. $T$ (Post-9-11), T' (Post-9-11) and Hypotheses V0-V2 are defined in Section IV. $* p<10 \%$, $* * p<5 \%$, *** $p<1 \%$

and therefore leads to greater volume in trading. It is the source of this expectation on the part of investors that is at issue. Indeed the source could be inside information about the impending attack. However, if the source of the increased implied volatility was independent of information of the impending attack then the results we have obtained may not support the insider trading hypothesis. As of this writing we have no plausible alternative hypothesis regarding the source of the increased VIX in 2001.

We note the proviso that we should accord greater weight to the option volume to detect 9-11 inside traders, and use VIX as a reference only. The increase of VIX may be due to the fall of interest rates, industrial production or oil prices. It may also be attributed to the rise of unemployment rate or other factors. As such, VIX is not reliable in detecting 9-11 inside traders.

Finally, the results from the non-parametric test statistics which we apply are basically consistent with the results of the t-statistics. As volumes per contract and VIX are expected not to be normally-distributed, though t-statistic is still valid for non-normality assumption under central limit theorem, it is still good to include the results of non-parametric statistics for comparison. In this paper, we only report the results for Wilcoxon statistic in tables 5A, 5B and 6 as the results of all other non-parametric statistics produce similar $\mathrm{p}$-values and lead us draw the same conclusion as Wilcoxon statistics. Basically, 
the results drawn from Wilcoxon statistic are qualitative consistent with those drawn from t-statistic. The difference is that sometimes the results from t-statistic show insignificant whereas those from Wilcoxon statistic show marginally significant, for example, $T(4+)$ of OTM in table 5A, and sometimes the results from t-statistic show strongly significant whereas those from Wilcoxon statistic show marginally significant, for example, $T(1 \mathrm{~A})$ of OTM in table 5A. On the other hand, sometimes the results from t-statistic show marginal significant whereas those from Wilcoxon statistic show strongly significant, for example, $T(3 \mathrm{~B})$ of ATM in table 5A. As the power of non-parametric tests is lower than that of the parametric tests, the results of the non-parametric tests will only be used as a reference to double check the results from the $\mathrm{t}$-statistics and we will use the results from the t-statistics to draw our conclusion.

\section{Conclusions}

This study examines the trading activities of options on the Standard \& Poor's 500 Index which are traded on the CBOE. SPX index options offer readily available and flexible tools for investors who had prior knowledge about the 9-11 attacks to reap speculative gains in the aftermath of the attacks.

Our findings lead us to conclude that there are abnormal trading volumes in September 2001 OTM, ATM and ITM SPX index put options, and September 2001 ITM SPX index call options in 2001 near the 9-11 attacks and after the 9-11 attacks. These abnormal trading volumes are consistent with three bearish speculative strategies, that are Put Purchase, Put Bear Spread, and Naked ITM Call Write. However, our findings do not reject the hypotheses that there is no abnormal trading in September 2001 OTM and ATM SPX index call options prior to the 9-11 attacks. In addition, our findings from testing the CBOE VIX also are consistent with the results of the Student's t-tests and non-parametric tests.

At issue is whether we could credibly extrapolate our findings on abnormal trading to substantiate claims that insiders were active in the options market trying to profiteer from anticipated fallout post-9-11 attacks. We take the view that although we could not prove definitively that insiders were at work, our findings provide credible circumstantial evidence to support of the insider trading claim. Consider a possible 
counter-argument that the abnormal trading volume in the option contracts prior to the 9-11 attacks was due to the falling equity market or other factors contributing to negative market outlook. The following constitutes credible reasoning to refute the declining market argument: (1) the market was falling in both the periods of 2000 and 2001 in our study; (2) the trading volumes were consistent for the periods from the first day of trading up to three calendar months prior to September 11, 2000 and September 11, 2001, respectively; but (3) there was abnormal trading volume in the September 2001 SPX index options within the immediate window of up to 3 calendar months prior to the 9-11 attacks; and (4) there was abnormal trading volume in the post 9-11 periods in 2001.

Finally, we reiterate that our findings show that there was a significant abnormal increase in the trading volume in the option market just before 9-11 attacks in contrast with the absence of abnormal trading volume far before the attacks. This only constitutes circumstantial evidence that there were insiders who tried to profit from the options market in anticipation of the 9-11 attacks. More conclusive evidence is needed to prove definitively that insiders were indeed active in the market. Although we have discredited the possibility of abnormal volume due to declining market, such investigative work would still be a very involved exercise in view of the multitude of other confounding factors e.g. coincidence, confusing trading strategies intentionally employed by the insiders, noises from the activities of non-insiders.

Accepted by: Prof. P. Theodossiou, Editor-in-Chief, January 2008

\section{References}

Arvedlund, E. E. 2001. Follow the money: terrorist conspirators could have profited more from fall of entire market than single stocks. Barron's, October 8.

Davison, A., and Hinkley, D. 1997. Bootstrap methods and their applications. Cambridge: Cambridge University Press.

Day, T. E., and Lewis, C. M. 1988. The behavior of the volatility implicit in the prices of stock index options. Journal of Financial Economics, 22, $103-122$.

Eckbo, E.; Masulis, R.; and Norli, O. 2000. Seasoned public offerings: Resolutions of the 'New Issue Puzzle'. Journal of Financial Economics, 56, 251-291.

Efron, B., and Tibshirani, R. 1993. An introduction to the bootstrap. Chapman 
\& Hall.

Etling, C., and Miller Jr, T. W. 2000. The relationship between index option moneyness and relative liquidity. Journal of Futures Markets, 20(10), 971-987.

Fernandes, A. C., and Machato-Santos, C. 2002. Evaluation of investment strategies with options. European Financial Management Association London Conference, Working Paper.

Gemmill, G. 1996. Did option traders anticipate the crash? Evidence from volatility smiles in the UK with US comparisons. Journal of Futures Markets, 16(8), 881-897.

Harvey, C. R., and Whaley, R. E. 1991. S\&P 100 index option volatility. Journal of Finance, 46(4), 1551-1561.

Hollander, M., and Wolfe, D. A. 1973. Nonparametric Statistical Methods, John Wiley \& Sons, New York.

Hull, J. C. 1998. Introduction to futures and options markets. Third Edition. NY: Prentice-Hall.

Ikenberry, D.; Lakonishok, J.; and Vermaelen, T. 1995. Market underreaction to open market share repurchases. Journal of Financial Economics, 39, 181-208.

Isakov, D., and Morard, B. 2001. Improving portfolio performance with option strategies: Evidence from Switzerland. European Financial Management, 7(1), 73-91.

Lyon, J.; Barber, B.; and Tsai, C. L. 1999. Improved methods for tests of long-run abnormal stock returns. Journal of Finance, 54, 165-201.

MacKinlay, A. C. 1997. Event studies in economics and finance. Journal of Economic Literature, 35(2) 13-39.

McMillan, L. G. 1996. McMillan on options; NY: John Wiley.

Merton, R; Scholes, M; and Gladstein, M. (1978). The returns and risk of alternative call option portfolio investment strategies. Journal of Business, 51, 183-242.

Merton, R.; Scholes, M.; and Gladstein, M. 1982. The returns and risk of alternative put option portfolio investment strategies. Journal of Business, $55,1-55$.

Morard, B., and Naciri, A. 1990. Options and investment strategies. Journal of Futures Markets, 10, 505-517.

Poteshman, A. M. 2006. Unusual Option Market Activity and the Terrorist Attacks of September 11, 2001, Journal of Business, 79, 1703-1726.

Sheikh, A. M. 1989. Stock splits, volatility increases, and implied volatilities. Journal of Finance, 44(5), 1361-1372.

Stoll, H. R., and Whaley, R. E. 1991. Expiration-day effects: What has changed? Financial Analysts Journal, 58-72.

Sutton, C. 1993. Computer-intensive methods for tests about the mean of an asymmetrical distribution. Journal of the American Statistical Association, $88,802-808$. 
Trennepohl, G., and Dukes, W. 1981. An empirical test of option writing and buying strategies utilizing in-the-money and out-of-the-money contracts. Journal of Business Finance and Accounting, 8(2), 185-202.

Virgo, J. M. 2001. Economic impact of the terrorist attacks of September 11, 2001. Atlantic Economic Journal, 29(4), 353-357

Yates, J. W., and Kopprasch, R. W. 1980. Writing covered call options: Profits and risks. Journal of Portfolio Management, 6, 74-79. 